\title{
SPRACHARBEIT IM DIENST DES NS-STAATS 1933 BIS 1945
}

1. Einleitung

2. Annotierte Bibliografie

3. Einordnung und Bewertung

3.1. Selbstverständnis

3.1.1. Byzantinische Germanistik oder wie man sich andient

3.1.2. Sprachideale und ihre Funktion

3.1.3. Leitfadenlinguistik

3.2. Sprachbegriff: Gemeinschaft - Rasse - Volksgeist

4. Beobachtungen zur Beschreibungssprache

Literaturverzeichnis

\section{Einleitung}

,Deutsch von 1933 bis $1945^{\circ}$ ist ein Thema, das die Forschung nach 1945 bisher in zweierlei Hinsichten beschäftigt hat.

Erstens und zunächst die Sprache dieser Zeit, zuallererst Nazi-Sprache (Berning 1964, zuletzt die Sammlung von Brackmann/Birkenhauer 1988). Erst in jüngster Zeit interessieren - pragmatisch beschrieben - auch diejenigen sprachlichen Ausdrucksformen, die nicht Nazi-Sprache sind. Spezifische kommunikative Erscheinungsformen unter den Bedingungen des Nationalsozialismus sind dann der Gegenstand (Bauer 1988, verschiedene Beiträge in Ehlich 1989; zuvor Maas 1984 und zuletzt 1991). Hinzu kommt, im Sinn einer Fortschreibung der von Sternberger, Storz und Süskind verfolgten Konzeption, die Kontrolle des Fortbestands: Welches Nazi-Vokabular wird bis in die Gegenwart und mit welcher Bedeutung gebraucht? (Vgl. dazu etwa Stötzel 1988.)

Zweitens ist das Interesse auf die Wurzeln des Fachs gerichtet, um daraus seine Stellung im und zum Nationalsozialismus zu erklären. Die nationale Wissenschaft der Germanistik wird dabei methodisch und inhaltlich hinsichtlich ihres ideologischen Gehalts überprüft, und man wendet sich Namen und Personen zu, sucht Affinitäten, Geistesverwandtschaften, Bekenntnissen bis hin zu vorbehaltlosen Teilnahmen nachzuspüren, m. a. W. Graden von Belastetsein $^{1}$ - mit dem Ziel, Wissenschaft von der ideologischen Schlacke zu befreien, soll heißen: wissenschaftliche Erkenntnisse, ihre Seriosität und damit

${ }^{1}$ Ziegler beschreibt drei Stufen: „die Haltung völliger sachlicher Integrität [...] die gleichsam mittlere Haltung einer gewissen Anpassung an die nationalsozialistische Ideologie [...] die extreme Haltung einer bewußten und betonten, unleugbar freiwilligen und totalen Identifizierung der eigenen Forschung [...] mit der nationalsozialistischen Ideologie“ (Ziegler 1965, 148 f.). 
ihren gültigen Wert zu fixieren (Ziegler 1965, v. Polenz 1967, heute vor allem Simon 1979, 1982, 1985, 1986, 1989, Römer 1985, Maas 1988 a und b, Steger 1989; vgl. auch Wigger 1982).

Wir sehen: Die mehr oder weniger wissenschaftliche Betrachtung der Sprache von 1933 bis 1945 durch Zeitgenossen ist ein bisher unbeachtet gebliebenes Thema der Historiografie unseres Fachs. Wir nähern uns ihm vorläufig in Form einer annotierten Bibliografie mit anschließendem Kommentar ${ }^{2}$. Dabei gilt es auch, Merkmale nationalsozialistischer Sprachwissenschaft aus ihren Fragestellungen, Gegenständen und Ergebnissen abzuleiten. Wie sonst sollte denn auch die Geschichte dieser Wissenschaft von 1933 bis 1945 geschrieben, diese selbst in ihrer Zeit beschrieben werden? Wir legen also eine Bibliografie zu Arbeiten vor, die zwischen 1933 und 1945 entstanden sind und die entweder sprachtheoretische Positionen darlegen oder die sprachliche Gegenwart 1933 bis 1945 beschreiben ${ }^{3}$. Insofern wenige zeitgenössische Darstellungen zur Sprache 1933 ff. existieren (vgl. Simon 1989, 67), konnten Arbeiten in diese Gruppe uneingeschränkt aufgenommen werden - daß wir sie vollständig dokumentieren, wollen wir damit nicht behaupten. Es sind also stets solche Arbeiten berücksichtigt, die, etwa in Vorworten, auf irgend eine u. U. recht implizite Weise am Titel bzw. aus dem Abstract der Bibliografie nicht unbedingt ablesbare Affinität zum Nationalsozialismus dokumentieren (etwa [3], [10]). Eine Auswahl haben wir getroffen in bezug auf die sprachtheoretischen Beiträge. Die ideologische Verwurzelung in die Weltsicht des

${ }^{2}$ Quellenangaben erfolgen dabei entweder, wenn es sich um Sekundärliteratur handelt, in der üblichen Form: Verfassername, Jahres-, Seitenzahl in runden Klammern; oder, wenn es sich um einen in der Bibliografie dokumentierten Beitrag handelt: durch Komma getrennte Zahlen in eckigen Klammern, wobei die Zahl links des Kommas die Nummer des Beitrags in der Bibliografie, die rechts des Kommas die Seitenzahl ist. Für die gründliche Recherche der Titel und den ersten Entwurf einer kurzen Charakteristik dieser Titel danke ich stud. phil. Michael Ullrich.

${ }^{3}$ Beiträge aus der Rubrik ,Fremdwortlinguistik' sind nur in Auswahl dokumentiert. Purismus ist ein seit dem 17. Jh. fortgeschriebenes Kapitel der Sprachwissenschaft. Das Jahr 1933 hat hier keine Veränderung zur Folge, und schon gar keine im Sinne der Puristen - eine gewisse Fremdwortfreundlichkeit der Nazis ist bekannt. Der Purismus $1933 \mathrm{ff}$. steht vielmehr vor allem in unmittelbarer Tradition des Allgemeinen deutschen Sprachvereins. Dessen Mitglieder - und die zahllosen fremdwortfeindlichen Beiträge in seiner Zeitschrift ,Muttersprache' belegen dies - sahen in der Fremdworthatz eine Chance, sich dem Nationalsozialismus anzudienen. Der Nazigermanistik im eigentlichen Sinn gehört dieses Thema insofern eher peripher an. ,Propagandalinguistik' fehlt in dieser Übersicht gänzlich, und zwar deshalb, weil ausgesprochen linguistische Reflexionen fehlen. So unermüdlich das Thema ,Propaganda ' in verschiedensten Hinsichten abgehandelt ist - in rein sprachwissenschaftlicher wohl nicht. Drittens schließlich haben wir die beiden frühen Beiträge aus dem sprachwissenschaftlichen Widerstand (Jacob 1938, Paechter 1944) nicht in die Bibliografie (wohl aber ins Literaturverzeichnis) aufgenommen. Obwohl zeitgenössische Sprachreflexion - ihre nationalsozialistischem oder verwandtem Sprachdenken entgegengesetzte Geisteshaltung rechtfertigt nicht, sie einzureihen in die Riege der affirmativen Beiträge. 
Nationalsozialismus war auch hier Kriterium. Die Zahl dieser Arbeiten häufig kürzere Beiträge in ,Muttersprache', ,Zeitschrift für Deutsche Bildung', ,Nationalsozialistische Literatur' u. a. - ist Legion, die Vielzahl von Publikationen der ideologischen Germanistik aus der Zeit von 1933 bis 1945 unüberschaubar. Von daher mag die Auswahl gering erscheinen. Sie ist zu groß angesichts der ermüdenden Monotonie und Unoriginalität, mit der das jeweilige Thema vor dem Hintergrund der nationalsozialistischen Ausrichtung behandelt wird. Zu welchem Gegenstand immer: Diese Veröffentlichungen lassen sich sowohl methodisch als auch hinsichtlich ihrer Kernaussage auf bloße Stereotype reduzieren. Die Gleichschaltung der Germanistik und ihre ideologische Ausrichtung auf den nationalsozialistischen Staat, m. a.W. ihre politische Befangenheit, verhindern die originelle Behandlung sprachwissenschaftlich interessierender Themen. Was die von 1933 bis 1945 ideologisierte Sprachwissenschaft kennzeichnete, beruht auf einer abstrusen Version einer phänomenologisch ausgerichteten, romantisch getönten, nationalistisch durchsetzten Germanistik. Solche Art Sprachreflexion 1933 bis 1945 vermittelt ein Bild von der Selbsteinschätzung des Fachs, und wir erhalten Aufschluß über die Weltsicht seiner Vertreter. Wir erleben Reflexion des Unrechts, der Lüge, der Unmenschlichkeit in der Hülle der Wissenschaft ${ }^{4}$.

\section{Annotierte Bibliografie}

[1] Ahmels, Herbert: Sprecherziehung im Dienste der politischen Arbeit. In: Das gesprochene Wort. 2. Jg. 1939, 139-145.

Von ,Schulung zur Hochlautung' handelt dieser Beitrag. Er erläutert eine Maßnahme des Heimatwerks Sachsen ,auf Anordnung des Gauleiters innerhalb der NSDAP“ (139). Sie soll dazu dienen, den ,Volksgenossen ' - im Artikel werden erwähnt Soldaten, SAMänner, Frauen, spez. Hausfrauen, Kinder - ein sprechsprachliches Leitbild zu vermitteln. Da die nationalsozialistische Zukunft dem Kampf gehöre, der den ,heldische[n] und kämpferische[n] Mensch[en]“ (141) verlange, heißt das Sprechideal: „kernig, hart, straff, klar, bündig und wirksam“ (141).

[2] Bergmann, Karl: Der Deutschen wehrhafter Geist im Spiegel der Sprache. In: Zeitschrift für Deutschkunde. 49. Jg. 1935, $201-207$.

Ein die Etymologie, Morphologie und Semantik bemühender Versuch, martialisches Sprechen mit germanischer Mentalität zu begründen: der stete Existenzkampf der Germanen hätte die Ausbildung eines kriegerischen Wortschatzes gefördert, den Vf. in übertragenen Gebrauchsweisen der Gegenwart von 1935 aufspürt. Kriegsmetaphern seien erfreulicherweise vor allem seit dem „Aufbruch [...] der Nation zum Dritten Reich“ (203) - sein Selbstverständnis als Kampf dokumentierend - wieder aufgeblüht. Beispiele aus allen Bereichen des Nazi-Alltags werden gegeben (Generalangriff, Arbeits-, Getreide-, Kartoffelschlacht, Arbeits-, Elektrofront), um abschließend, mit Luther, Bismarck und den Kriegsberichten des Hauptquartiers aus dem ersten Weltkrieg, historisch legitimierte Vorbilder zu zitieren.

${ }^{4}$ Vielleicht kann diese Arbeit insofern einen Beitrag liefern zu einem von R. Römer gestellten Thema: „Über die nationalsozialistische Beeinflussung der Sprachwissenschaft hat es in Deutschland bisher keine Diskussion gegeben“ $(1985,179)$. 
[3] Bertsch, A.: Wörterbuch der Kunden- und Gaunersprache. Berlin 1938.

Die mehr als zwanzigjährige Tätigkeit des Pfarrers B. als Hausgeistlicher im Zuchthaus Ludwigsburg und in der Invalidenstrafanstalt Hohenasperg wurde ihm zur „kundenund gaunersprachlichen Hochschule“ (12). Als Ortsschulaufseher ,in einer zu zwei Fünfteln von Juden durchsetzten Gemeinde“ (12) konnte B. seine ,geheimsprachlichen Studien“ (12) fortsetzen und „durch Belauschen des Handelsverkehrs der semitischen Rasse“ (12) entdeckte er, „daß die Kunden- und noch mehr die Gaunersprache in keiner anderen Sprache so verwurzelt war, wie im Hebräischen“ (12). Ergebnis seiner langjährigen Erfahrung mit der "Gaunersprache“ ist dieses hauptsächlich aus Substantiven bestehende „deutsch - jenische Wörterbuch“ (14). Es ist als Hilfsmittel für Kriminalisten gedacht. B. konstatiert, daß im Gegensatz zur Kundensprache mit der „Seßhaftmachung der Juden“ (13) die Gaunersprache ins Stocken geraten sei: „Die Kenner derselben unter den Gaunern sind wohl im Rückgang begriffen" (13f.).

[4] Blunck, Hans Friedrich: Ein Volk: eine Sprache. In: Muttersprache. 49. Jg. 1934, H. 3, 65-68.

Dieser Auszug aus dem Vortrag ,Deutsche Kulturpolitik‘ von H. F. Blunck (Obmann der Reichsschrifttumskammer) enthält massive sprachpuristische Angriffe gegen den Gebrauch der „romanischen Fachwörter" (67) im Erziehungs- und Verwaltungswesen, im militärischen und im kulturellen Bereich. Die Nachahmung fremder Formen habe zu einer Verflachung der deutschen Kultur geführt. Blunck sieht in der Einführung romanischer Fachtermini eine Herabwürdigung der deutschen Kultur, denn es sei der Eindruck entstanden, daß die nordischen Länder die romanische Kultur nur übernommen und bestenfalls weitergeführt hätten. Darüber hinaus erzeugten die Kastenwesen und Bildungsdünkel fördernden Fremdwörter eine das Volk spaltende Kluft zwischen Proletariat und den ,in den hohen Schulen Erzogenen“ (65).

[5] Bues, Manfred: Die Versportung der deutschen Sprache im 20. Jahrhundert. Diss. Greifswald 1937.

Unter „Versportung der Sprache“ versteht Vf. den „merkbare[n] Einfluß des Sports auf die außersportliche Sprech- und Schriftsprache“ (11). Der erste Teil der Untersuchung enthält einen kursorischen Überblick über die Entwicklung der Sportsprache vom 18. Jh. bis zu den Olympischen Spielen 1936. Im zweiten Teil wird der Einfluß der Sportsprache, die B. als Sondersprache definiert, auf Umgangssprache, Zeitungssprache, Militärsprache (bzw. Soldatensprache) und Dichtung untersucht. Vf. kommt zu dem Schluß, daß Sport im Sinne des Nationalsozialismus ein notwendiger Bestandteil des deutschen Kulturlebens sei. Daraus ergebe sich geradezu die Notwendigkeit einer ,Versportung der Sprache“, die Vf. als „Blutauffrischung“ (98) wertet.

[6] Cretius, Paul: Deutschunterricht. Deutsches Wesen - Deutsche Sprache. Osterwieck 1934.

Konglomerat didaktischer und sprachwissenschaftlicher Themen. Dem Deutschlehrer werden Ratschläge für den Sprechunterricht erteilt. Außerdem erhält er Übungsvorschläge für die Aufsatz- und Diktatgestaltung, gespickt mit puristischen Ermahnungen. Ferner liefert C. eine sprachgeschichtliche Untersuchung von Wortschatz, Phraseologismus und Mundart sowie Anmerkungen zu Wortbildung, Familiennamen und Ortsnamen. Dem Geist der Zeit folgend erkennt C. in der deutschen Sprache „Ausdruck deutschen Wesens“, eine Offenbarung des „Volkscharakters“.

[7] Darnedde, Dr. Lothar: Einfache und klare Sprachhaltung. In: Nationalsozialistische Monatshefte. 39. 1937, 1073 (17) - 1082 (26).

Funktionsverbgefüge, „Hauptwörterei“ (1075), „Abkürzungssucht“ (1078) und „Fremdwörterei“ (1080) - diese Standardthemen der sich zur Sprachpflege berufen fühlenden Sprachbetrachter sind auch Gegenstand dieses Beitrags. Deutsche Art (i. e. National- 
sozialismus) und jüdisches Wesen - diese stets bemühte Polarisierung des dem Nationalsozialismus in wissenschaftlichem Gewand das Wort Redenden stattet seine Argumentation aus. Vf. gibt als „rassisch“ (1074) bestimmtes Ziel von Sprachpflege vor: die hinlänglich bekannten Merkmale „Einfachheit und Klarheit“ (1074).

[8] Deubel, Werner: Die Gaunersprache. In: NS-Rechtsspiegel. München, 2. Jg. 1938, Nr. 4, S. 3.

Antisemitischer Hetzartikel, der, wie zu erwarten, eine Verbindung zwischen Judentum und Gaunertum herzustellen versucht: Der verbrecherische Charakter der Juden zeige sich darin, daß die Gauner gerade aus dem Hebräischen ihre Fachausdrücke entlehnten.

[9] Drube: Sprache, Geist, Volk. In: Nationalsozialistisches Bildungswesen. 4. Jg. 1939, $358-365$.

D. vertritt in diesem an Humboldt orientierten ,sprachphilosophischen' Beitrag die These, daß die Sprache das wichtigste Bindeglied für den Zusammenhalt eines Volkes ist. Die beiden Aspekte des Humboldtschen Sprachbegriffs erscheinen hier: einerseits, wenn die volkschaffende und -erhaltende Kraft der Sprache herausgestellt wird; andererseits rassenideologisch verfremdet: Volk und Sprache könnten nicht „von den rassischen Bedingtheiten“ (364) getrennt werden, jede Sprache sei der Spiegel eines bestimmten Weltbildes. Der Ursprung der unterschiedlichen völkischen Weltanschauungen liege jedoch in der Rasse.

[10] Feuring, Adolf/Heinrich Korte: Bürokunde und Amtssprache. Berlin-Wien 1943.

Korte versteht seinen Beitrag zur Amtssprache (101-124) eher als Ratgeber denn als Lehrbuch der deutschen Sprache. Der Autor fordert eine knappe und klar verständliche Amtssprache. Der „schwülstige und breitspurige Amtsstil“, „Hauptwörtersucht und Schachtelsätze“ müßten bekämpft werden. Die Sprachbeispiele werden in einer ,richtig'-,falsch'-Synopse gezeigt.

[11] Fischer, Walter: Meldung und Befehl. In: Volk im Werden. 3. Jg. 1935, 374-378.

Vf. unternimmt den Versuch, die Textsorten ,Meldung ' und ,Befehl' als literarische Ausdrucksformen auszuweisen und damit aufzuwerten. Wer Befehlsträger sei, müsse nicht nur wortgewaltig (,Meldung'), sondern auch fähig sein, mit seiner Wortgewalt neue Welten zu schaffen (,Befehl'). Dies könne nur der Dichter, denn Meldung und Befehl seien „dichterische Grundhaltungen“. Diese Einheit von Wortgewalt und schöpferischer Kraft herzustellen, sei erst im Nationalsozialismus möglich, der mit seinem „Grundgesetz der vollkommenen Einheit“ (377) die Voraussetzung für die Aufhebung dieser Spaltung in der Dichtung geschaffen habe.

[12] Geißler, Ewald: Sprachhege und Sprechtiefe. In: Muttersprache. 50. Jg. 1935, H. 3, 65-74.

Einer der unzähligen Beiträge, die Herders und Humboldts Sprachbegriff - in der Sprache drückt sich der,Geist' eines Volkes aus - in das nationalsozialistische Weltbild einzupassen versuchen. Angriffspunkt hierzu bietet dem Verfasser auch dieses Aufsatzes das Esperanto, außerdem „Aküwort, Fremdwort und unechtes Hauptwort“ (67). Dem setzt G. ein stilgerichtetes Sprachdenken entgegen, der Vorstellung folgend, daß sich der Geist über den Stil ausdrückt und zwar besonders im gesprochenen Wort: „Das Sprechen ermißt den Tiefengehalt von Wörtern und Sätzen!“ (73).

[13] Geißler, Ewald: Vom deutschen Stil. Lockrufe und Warnungen. Leipzig 1937.

G.s Arbeit war eigentlich (in gekürzter Fassung) die Einleitung zum Duden-Stilwörterbuch. Der Vf. war ursprünglich als Leiter des Sprachamts der Deutschen Akademie das nicht verwirklicht wurde - vorgesehen. Dieser Beitrag ist eine Anleitung zum Schutz der deutschen Sprache vor der „Mißhandlung“ durch „Sprachdummheiten“. 
Dieser punktuell ansetzende Sprachlenkungsversuch kommt über ästhetisierende Geschmacksurteile (,schön', ,häßlich') nicht hinaus. Geißler, Inhaber der damals einzigen Rhetorik-Professur in Deutschland, wendet sich gegen ,volksfremde Humanisterei, Französelei und technische Internationalität, geblähtes Behördengetu und Zeitungsgeschwätz“, denn dahinter wittert er „Dünkel“ und „Unfähigkeit zu Volksnähe und Gemeinschaftsdenken“. Er fordert einen knappen und gedrängten Schreibstil, lehnt Häufungen, Superlativ, Schwulst, ,Aküwörter' und Fremdwörter ab.

[14] Götting, Ludwig: Die Sprache des Arbeitsdienstes. In: Jahrbuch der deutschen Sprache. Bd. 2, 1944, 199-203.

Die Begriffs- und Wortbildung des Arbeitsdienstes, die Sprache des „Arbeitsmannes“ (200) sei aus dem Zusammenleben in der Gemeinschaft und dem geordneten Tagesablauf entstanden. Kennzeichen dieser Sprache sei eine „gesunde echte Derbheit“ (201) und eine vom Arbeitsleben geprägte Metaphorik, die auch die Sprache von Hitlerjugend und Wehrmacht prägten. Sie sei „lebendig, heiter, wandlungsfähig und formenreich wie das Leben in der Gemeinschaft des Reichsarbeitsdienstes, zuchtvoll und bestimmt wie seine Gesetze“ (203).

[15] Götze, Alfred: Deutscher Krieg und deutsche Sprache. Rede zur Grimmfeier der Universität Gießen, gehalten am 11. März 1940. In: Giessener Hochschulgesellschaft. Nachrichten 15, 1941, 20-33.

Götze propagiert die sprachpuristische Reform der deutschen Heeressprache. „Nicht nur Deutsche kämpfen gegen Engländer und Franzosen, auch Deutsch kämpft gegen Englisch und Französisch“ (20). Der Krieg als „geistige Macht“ (25) habe zwar die deutsche Sprache positiv beeinflußt und bereichert, als historische Realität habe er sie jedoch verwüstet und beraubt. Besonders seit dem Dreißigjährigen Krieg seien ,militärische Fremdlinge“, die zur „schlimmsten Verwelschung“ (27) geführt hätten, in die deutsche Heeressprache gelangt. Götze ist aber überzeugt, daß der zweite Weltkrieg die Militärsprache von den Fremdwörtern befreien werde.

[16] Hack, B.: ,Blut und Boden' in der deutschen Sprache. In: Muttersprache. 52. Jg. 1937, H. 5, 179--182.

Vf. durchforstet den deutschen Wortschatz nach gleichsam nationalsozialistischen Ideologemen, m. a.W.: er versucht, die nationalsozialistische Weltsicht in der deutschen Sprache zu verwurzeln, jene mit dieser zu legitimieren, um feststellen zu können: „Nationalsozialistisches Wollen und deutscher Sprache Urtum kommen in eins" (180). Er wird natürlich fündig: Das ,Blut-und-Boden-Wortfeld“ - „hier scheint die ,Transzendenz' des deutschen Seins durch" (181) - bietet Vf. Gelegenheit, den Kausalzusammenhang zwischen deutscher Sprache und Naziideologie herzustellen.

[17] Haensel, Carl/Richard Strahl: Politisches ABC des Neuen Reiches. Stuttgart 1933.

Von Abbau bis Zoll werden 132 den Nationalsozialismus tragende Begriffe erklärt. Die Fragen des Titelblatts ,Was heißt ...', ,Was ist ...' zeigen einmal mehr: der Nationalsozialismus verstand sich als absolute Daseinsform, der die Wirklichkeit neu festlegte.

[18] Ha upt-Heydemarck, Georg: Soldaten-Deutsch. Berlin 1934.

Dieses Wörterbuch der Soldatensprache dokumentiert deren typische Verflechtung von Zynismus, Vulgarität und Galgenhumor (entsprechend die Illustrationen). Die Wörter und idiomatischen Wendungen werden durch einfache Übersetzungen, Synonyme oder lexikalische Paraphrasierungen erklärt. Meist geben ,kleine Geschichten' oder Soldatenlieder (mit Noten) zudem Aufschluß über Gebrauchsweisen.

[19] Hunger, Karl: Erziehung zur volkstümlichen Hochsprache. In: Zeitschrift für Deutsche Bildung. 15. Jg. 1939, 294-305.

Vor dem ,nationalsozialistischen Umbruch“ (204) habe es eine Spaltung in der Sprachund somit auch in der Volksgemeinschaft gegeben. Der Nationalsozialismus habe die 
sozialen Gegensätze zwischen den einzelnen Volksschichten in der Volksgemeinschaft aufgehoben. Die volkstümliche Hochsprache habe nun die Aufgabe, die Sprachgegensätze dieser sozialen Gruppierungen aufzuheben. H. versucht, die ,volkstümliche Hochsprache" lexikalisch und syntaktisch zu bestimmen und grenzt sie ab einerseits von der Mundart, als untere Sprachgrenze, andererseits von der ,Gebildetensprache' sowie von der ,Fachsprache der Wissenschaft', als obere Sprachgrenze.

[20] Ibel, Rudolf: Bildgeheimnis und Wirkung der Sprache. In: Zeitschrift für Deutschkunde. 49. Jg. 1935, 470-475.

Sprache sei „das sprechendste Zeugnis unseres seelischen und geistigen Werdens“ (470) - damit ist einmal mehr ein Beitrag vorgelegt, welcher der Vorstellung Humboldts und dann Voßlers folgend die sprachprägende und wirklichkeitschaffende Kraft von Geist und Volkscharakter voraussetzt. Daran angehängt der Kotau: „Der denkende Geist (und damit der urteilende und handelnde) lebt von Gnaden der heiligen Mächte der Wirklichkeit, die der Nationalsozialismus Blut, Boden, Art und Rassenseele nennt" (470).

[21] Kammerer, Friedrich: Die deutsche Anrede im Wandel der Zeit. Eine sprachgeschichtliche Betrachtung. In: Zeitschrift für Deutsche Bildung. 15. Jg. 1939, 420-424.

Die Verfügung des Oberkommandos des Heeres (1936) und der Erlaß des Reichsinnenministers (1938), wonach Vorgesetzte nicht mehr in der dritten Person anzureden sind, waren der $A$ nlaß für diesen sprachgeschichtlichen Überblick über Entstehung und Entwicklung der verschiedenen Anredeformen ( $\mathrm{Du}, \mathrm{Ihr}, \mathrm{Er}, \mathrm{Sie})$. In der Deutschen Burschenschaft, in der Turnerschaft, in der Jugendbewegung und natürlich in der nationalsozialistischen Bewegung, also zu „Zeiten idealistischen Aufbruchs“ (423), habe man zwar das Sie zugunsten des $D u$ bekämpft. K. plädiert dennoch für den Erhalt der zum Volkscharakter gehörenden beiden Anredeformen ( Du, Sie), denn „der Wert des von uns geliebten Du würde uns gar nicht bewußt werden, wenn es daneben nicht das Sie gäbe. Nur weil das Sie da ist, gibt es Du-Erlebnisse“ (424). Das Spannungsfeld zweier Anredeformen ermögliche die Beseitigung unnötiger Schranken, aber auch den Aufbau einer nötigen Distanz.

[22] Kempf, J.: Gutes Amtsdeutsch! Handbuch der deutschen Kanzleisprache. München 1934.

K. fordert eine „Heilung“ der Kanzleisprache von „Fremdwörtersucht“, „Juristendeutsch“ und „Bürokratenstil“. Richtigkeit, Reinheit, Deutlichkeit und Schönheit (bzw. Angemessenheit) sollten in Zukunft die Merkmale einer echt deutschen und volksverbundenen Behördensprache sein. Von grammatischen und stilistischen Normen ausgehend, demonstriert K. „abschreckende“ Negativbeispiele.

[23] Kiener, Franz: Die Zeitungssprache. Eine Deutung ihrer psychologischen Grundlagen. Diss. München 1937.

Diese Dissertation ist der Versuch, sozialpsychologische Grundlagen der Zeitungssprache aufzuzeigen. K. unterscheidet zwischen Gesinnungs- und Betrachtungszeitung mit je verschiedenen Ausdrucksformen. Sachlichkeits-, Polemik-, Feuilleton- und Propagandaoder Reklamestil werden als die vier Stilarten der Zeitungssprache herausgestellt. Dabei fließt Rassedenken ein, wenn K. verschiedene Menschentypen im Polemikstil von Zeitungen der Weimarer Republik widergespiegelt findet, Fremdwort, Schlagwort, Symbolwort als entsprechende Ausdrucksformen ausweist. Die Nachricht, als „grundlegende Seinsform der Zeitungssprache" (73), wird vom Bericht abgegrenzt, der sie immer mehr verdränge, dieser in die Unterarten Zustands-, Erlebnis-, Aufzählungsbericht unterschieden. Sie stellten die „inneren Formen der publizistischen Mitteilung in der Zeitung“ (69 ff.) dar. Die äußere Form macht Vf. abhängig von den beiden Hauptarten Gesin- 
nungs- und Betrachtungszeitung, jener weist er den Artikel, die Glosse, Interview und Kommentar als typische Textformen zu. Die Schlußbetrachtung ist auf Umstände gerichtet, „die die Sprache der Zeitung umgestalten oder verunstalten“ (103). Die psychoanalytischen Faktoren der Ermüdung und geistigen Verkümmerung - aufgrund des hohen Drucks, unter dem der Journalist arbeitet und des Zwangs, beim Schreiben immer mehr zu geben ohne die Möglichkeit zu nehmen und sich geistig aufzufrischen haben Einfluß auf den sprachlichen Ausdruck, ebenso ,andere [...] Sprachkreise [...]“ (109), der Rednerstil sowie die schöne Literatur. Abschließend bewertet Vf. die Funktion der Zeitung als „Ausdrucksmittel eines gemeinschaftlichen Bewußtseins“ (118) - im demokratischen Staat mit den Merkmalen Lebendigkeit und Mannigfaltigkeit mit der Gefahr, „zum Chaos [zu zersplittern]“ (118), im autoritären Staat mit den Merkmalen Ruhe, Einheitlichkeit, Uniformität. Antisemitische Entgleisungen - „Weil er [der Jude] kein eigenes Wesen hat, so kann er sich geschmeidig anderen Seelenarten anschließen" (41) - und einseitige nationalsozialistische Argumente - „Auf unser Volk gesehen [...] läßt sich zu jeder Zeit eine dumpfe Sehnsucht feststellen nach der großen Heimat aller deutschen Menschen und der deutschen Seele, die Sehnsucht [...] nach dem ,Dritten Reich" “(45) - machen auch diese Studie zum Problemfall.

[24] Kindt, Karl: Der Führer als Redner. Hamburg 1934. (Kürzere Fassung u.d.T. ,Der Führer spricht‘ in: Die neue Literatur. 35. Jg. 1934, 2-15).

K. erörtert anhand ausgewählter Textbeispiele (u. a. aus ,Mein Kampf ) Hitlers rhetorische Kunstgriffe. Die Schrift ist einseitig, überspannt und zynisch, Hitler wird maßlos verherrlicht und mythisiert (,demosthenische Redekunst'). Bemerkenswert ein Glossar, in dem die in dieser Arbeit verwendeten Fremdwörter übersetzt werden, denn zu ihrer unbedingten Meidung hat $\mathrm{K}$. sich nicht durchringen können.

[25] Kißling, Helmut: Sprache und Volksgeist. (Über neue Aufgaben der Sprachwissenschaft und des Sprachunterrichts). In: Die Neueren Sprachen 44, 1936, 339-356.

In dieser Arbeit geht es, entgegen dem Untertitel, hauptsächlich um sprachwissenschaftliche Erkenntnisse, weniger um die Aufgaben des Sprachunterrichts. Die Sprache sei vor der Rasse die größte Macht in einer Volksgemeinschaft. K. distanziert sich zwar von Schmidt-Rohrs Buch ,MutterSprache' und räumt ein, daß jede Sprache auf die Rasse zurückdeute, betont aber, daß erst die einheitliche Sprache einem Volk sein politisches Bewußtsein schaffe. Jedem Volk sei in seiner Sprache seine Weltanschauung niedergelegt, daher glaubt K., daß sich ,aus dem Kampfe um die Behauptung unseres Volkes" (355) zwangsläufig die Forderung nach einer genauen Kenntnis der inneren Begriffswelt feindlicher Völker ergebe.

[26] Köpke, Karl Heinrich: Die Verwendung von Führerworten im Schrifttum. In: Nationalsozialistische Bibliographie. 1934, H. 4, I-VIII.

K. stellt fest, daß man sich zu keiner Lebensfrage mehr äußern könne, ohne sich auf den Führer zu beziehen. Eine systematische Überprüfung habe jedoch ergeben, daß $80 \%$ aller ,Führerzitate falsch waren, wobei besonders der politische Gegner in seinen Oppositionsschriften die Worte des Führers verfälsche oder aus dem Zusammenhang reiße. K. zählt die häufigsten Zitierfehler auf, wie z. B. Kürzungen, falsche Exegese[!], Fremdwortverdeutschung, Stiländerung, Änderung des Datums. Der direkte Vergleich mit dem Original soll zeigen, daß eine scharfe Beobachtung aller ,Führerzitate im Schrifttum durch die Parteiamtliche Prüfungskommission notwendig sei.

[27] Krause, Konrad: Jüdische Fremdwörter in der deutschen Sprache. In: Der Weltkampf. 14. Jg. 1937, H. 166, 456-460.

Kurze Auflistung ,jüdischer" Wörter, die „unser judengegnerisches deutsches Volk unbesehen täglich im Munde führt“"(456). 
[28] Krause, Konrad: Die jüdische Namenwelt. Essen 1943.

Antisemitische Namenkunde - diese Monografie enthält das Erwartete: Um die „Judenabwehr“ (7) zu erleichtern, legt K. eine auf Vorurteile gestützte - „ist doch Berufsund Arbeitsfreude im handwerklichen Sinne niemals die starke Seite der Juden gewesen“ (63) - Sammlung von Namen vor, nach Herkunft und Bedeutung geordnet. Der Anhang enthält Kapitel wie „Juden als politische Mörder“, „Jüdischer Menschenhandel im Frühmittelalter“, „Verbrecherisches Treiben der Juden im alten Rußland“.

[29] Kühn, Georg: Der Befehl. Eine sprachkundliche Betrachtung. In: Zeitschrift für Deutschwissenschaft und Deutschunterricht. 1943, H. 3, 165-169.

K. untersucht Wortfeld, Grammatik und Stilistik der direktiven Sprachhandlung ,befehlen'. Der Befehl, konstitutiv für Erziehung, Schule, Partei, Staat und Wehrmacht, sei sprachliche Tat, so wie der Befehl des ,Führers' durch die Handlung des Volkes zur geschichtlichen Tat werde. Der Sprachstil sei Ausdruck des Charakters. Die Befehlssprache habe den Charakter des soldatischen Führers: „gerafft und zuchtvoll, klar und bestimmt, schlicht und schweigsam" (168). Die Untersuchung dient dem Zweck, ihren Schlußsatz - „Führer befiehl, wir folgen Dir“ - sprachwissenschaftlich zu legitimieren.

[30] Kullack, Max: Mündliche Stillehre und volkstümliche Hochsprache. In: Nationalsozialistisches Bildungswesen. 3. Jg. 1938, 80-88.

K. verwirft die traditionellen Stillehren, da sie die „,volksnahe Sprache“ diskriminierten und die "Sondersprache der Intellektuellen-Schicht" (81) aufwerteten und als Ideal darstellten. Ziel der Spracherziehung müsse die Lehre einer volksverbindenden ,volkstümlichen Hochsprache" sein, die K. von der „seelisch verarmten“ (85) Hochsprache der Intellektuellen unterscheidet. Im Gegensatz zur "farblosen Begriffswelt“ (84) der Wissenschaftssprache sei die volkstümliche Hochsprache gekennzeichnet durch „Nähe zum Gegenstand" (83), durch unmittelbare Beteiligung am Vorgang mittels anschaulicher Sprachformen. In einer mündlichen Stillehre komme es darauf an, die bildhafte Sprachfähigkeit zu schulen. Nachzuahmende Vorbilder seien u. a. die Eddasprüche, Sprichwörter, Grimms Märchen, H. Grimms, Volk ohne Raum‘.

[31] Linden, Walther: Wehrhafte Sprache. Sprachform der Heerführer und Kriegsdenker: In: Muttersprache. 55. Jg. 1940, H. 5, 65-68; H. 6, 81-84; H. 7, 97-100; H. 9, $129-133$.

L. untersucht in den ersten Abschnitten des Beitrags die militärische Sprache Schlieffens, Moltkes und Clausewitz'. Die ,Sprachuntersuchung' beschränkt sich auf Geschmacksurteile: „einfach, knapp und schlagend“ (65), „Sätze voller Bildkraft und geformter Anschauung“ (67), „der kraftvolle Ausdruck der Empfindung (...) inmitten der schlichten Sachdarstellung“ (82), „dem männlich beherrschten Wort“ (84) usw. Aber der Inhalt der zitierten Belege läßt den eigentlichen Zweck erkennen: Sie sind nichts als Kriegsapotheosen und Lob soldatischer ,Tugenden'. Im letzten Abschnitt untersucht L. die Sprache der deutschen Wehrmachtsberichte, in denen er einen "künstlerischen Sinn“ sieht - den Überfall auf Polen zu rechtfertigen ist das Motiv. Diese Berichte im Einklang mit dem Rundfunk als Mittel der Spracherziehung seien imstande, die letzten Überreste „artfremder" Sprachformen auszurotten.

[32] Linden, Walther: Was heißt ,Sprache unserer Zeit'? In: Muttersprache. 51. Jg. 1936, H. 7/8, 277-281.

Wesenszüge des Deutschen und damit auch der deutschen Sprache seien „Einfachheit, Natürlichkeit, Kraft und in Selbstzucht gebändigter Wille“ (277), auf Sprache bezogen kurz „Treffsicherheit“. Besonders die ,jüdische und westeuropäische“ Zersetzung in der Zeit von 1919 bis 1933 habe das Wesen der deutschen Sprache zerstört. Erhalten habe es sich ,außer in den staatlichen Kundgaben des deutschen Führers und seiner nächsten Getreuen vor allem in der arteigenen Dichtung“ (278): Löns, Burte, der spätere George, 
Hans Grimm, Hans Carossa, Will Vesper, Kolbenheyer bilden u. a. die hinlänglich bekannte Riege völkischer, dem Nationalsozialismus gefälliger Schreiber von deutscher Art - mustergültige Sprachbeherrscher im nationalsozialistischen Sinn.

[33] M. Fr.: Der Erlösungsbegriff in der Weltanschauung. In: Volk im Werden. 6. Jg. 1938, 449-452.

In diesem Beitrag wird der indische, der vorderasiatische und der griechische Erlösungsbegriff untersucht. Obwohl der Autor mit dieser rassistischen Schrift im ideologischen Fahrwasser des Nationalsozialismus schwimmt, wendet er sich gegen den inflationären Gebrauch des untersuchten Wortes, das er als inhaltsleer entlarvt. Einen „nordischen“ Erlösungsbegriff gebe es gar nicht, er „,ist [...] für den Germanen restlos artfremd und paßt in seine Weltanschauung überhaupt nicht hinein" (451).

[34] Manthei, Erhard: Die Sprache der Hitlerjugend. In: Jahrbuch der deutschen Sprache, Bd. 1, 1941, 184-190.

Dieser Beitrag ist der Versuch, die Sprache der Hitlerjugend von der Soldatensprache abzugrenzen. Übertreibung, Ehrlichkeit, Spott, Scherz und Modewörtersucht seien Merkmale der Hitlerjugendsprache. M. glaubt, daß sich die Umgangs- und Alltagssprache der Hitlerjugend ständig ändere, da der Jugendliche immer neuen Spracheinflüssen ausgesetzt sei. Dies zeichne die Sprache der Hitlerjugend vor der schablonenhaften Soldatensprache aus. Vf. bedauert, daß die ,Aküsprache' auch vor der Hitlerjugend nicht haltgemacht habe, hinter deren Gebrauch er so manche jugendliche Bosheit wittert (Schaf ,Scharführer', Hauptschaf ,Hauptscharführer').

[35] Marcus, Willy: Sprache und Krieg. In: Muttersprache. 55. Jg. 1940, H.11, $161-164$.

M. untersucht den Einfluß des Krieges auf das Zeitungsdeutsch. Er stellt fest, daß die Tagespresse immer noch zum Fremdwort neige, z. B. gebe es zahlreiche Ableitungen mit dem Suffix -ismus (Churchilismus, Katalanismus), denen er keine lange Lebensdauer voraussagt. Vf. vermerkt die zunehmende Bildung substantivischer Determinativkomposita (Europakrieg, Feindländer, Skandinavienfeldzug). Demgegenüber träten Verdeutschungen etablierter Fremdwörter in der Presse zurück (z. B. Judengegner statt Antisemit).

[36] Matschoß, Alexander: Der Einfluß des Weltkriegs auf die Sprache. In: Muttersprache. 52. Jg. 1937, H. 12, 450-455.

M. hält den Einfluß des (ersten) Weltkriegs auf die Umgangssprache insgesamt für eine Sprachbereicherung, der der abgehobenen hochdeutschen Sprache wieder den Stempel „,der Lutherschen Urwüchsigkeit und Derbheit“ (453) aufdrückte. M. unterteilt den Wortschatz der Heeres- und Soldatensprache in vier Gruppen: Fachausdrücke der Berufsfachleute, Wörter des „unbekannten Soldaten“, i. e. Soldatenspott (451), Ausdrücke der Kriegsschriftsteller sowie eine „merkwürdige [...] vierte [...] Gruppe von Wörtern, die im wahrsten Sinne des Wortes kriegsgeboren sind und Schlachtendonner atmen" (451). Vf. beschreibt die Lautmalerei der Kriegsschriftsteller (Zöberlein, Jünger) und das Verhältnis der Heeressprache zu Fremdwort, ,Papiersprache' und ,Aküsprache‘. Während die Heeressprache die Fremdwörter und die Papiersprache erfolgreich bekämpft hätte, sei die Aküsprache von ihr gefördert worden. M.s Feststellung zwei Jahre vor Kriegsausbruch, daß ein „Zukunftskrieg“ seine sprachlichen Schatten vorauswerfe, mag auf den Öffentlichkeitsgrad der nationalsozialistischen Kriegsvorbereitungen schlieBen lassen.

[37] Mehl, Erwin: Deutsche Leibeserziehung - deutsche Sprache. In: Muttersprache. 55. Jg. 1940, H. 4, $51-54$.

Der Sprachpurist M. erinnert an den Aufruf des Turnvaters Jahn aus dem Jahr 1816, von fremden Sprachen nicht das auszuleihen, was man von der Muttersprache reichlicher 
und besser haben könne. Er bedauert, daß es auch in völkischen Tageszeitungen immer noch Fremdwörter wie Disziplin, Cup, Athlet, Volleyball, Basketball, Baseball und dergleichen „fremdes Unkraut" (51) gebe. Der Leser müsse sich über die „Französelei im Fechten“, „Engländerei im Faustkampf", „Norwegerei im Schneelauf" (53) und andere „Kuckuckseier“ (54), welche die „Ausländerei“ ins Sprachnest gelegt habe, belehren lassen. Denn: „Fremde haben wieder schweres Leid über Zehntausende unserer Volksgenossen gebracht. Da empfinden wir Fremdes auch schwerer als in ruhigen Zeiten" (54).

[38] Müller, Karl: Unseres Führers Sprachkunst. Dresden 1935.

Diese Schrift ist nicht eine, wie der Vf. vorgibt, „,vorurteilslose Darstellung des Tatsächlichen“ (2), sondern, natürlich, die folgsame Verklärung der „herzerfrischende[n] Schreibweise“ (55) Hitlers. Dabei folgt Vf. dem Stil des Sprachvereins: Was die Sprachpfleger an Hitlers Sprache zu kritisieren hatten, ist offen beim Namen genannt und zugleich als entschuldbarer Schönheitsfehler bagatellisiert.

[39] Ostrop, Max: Die Sportsprache, eine neue deutsche Standessprache. In: Zeitschrift für Deutsche Bildung. 16. Jg. 1940, 59-63.

O. lobt als ,jüngste Standessprache“ (59) die „regelrechte, rein deutsche, gute und einwandfreie Sprache des Sports“ (60), die ursprünglich im 19. Jh. als „Importware“ (59) aus England eingeführt wurde. Er liefert Beispiele von Übersetzungen (,Verdeutschungen“) und „Eindeutschungen“"von Termini aus den Bereichen Fußball, Leichtathletik und Tennis. Der Sport habe aus sich selbst heraus einen eigenen „Jargon“ geschaffen, der selbständig neben der amtlichen Fach- und Schriftsprache des Sports stehe und inzwischen die muttersprachliche Umgangs- und Schriftsprache positiv beeinflußt habe. „Wie Kampfbereitschaft die Grundhaltung des Sportlers ist, so wird auch dieses Kämpferische der Sprache ihren Charakter aufdrücken und dadurch das germanische Wesen unserer Sprache hervorheben und stärken" (63).

[40] Panzer, Friedrich: Sprache und Volksseele. In: Zeitschrift für Deutsche Bildung. 13. Jg. 1937, $377-389$.

Eine sich an Herder orientierende Arbeit, in der Panzer (1933 Vorsitzender der Gesellschaft für Deutsche Bildung) wie alle ideologischen Sprachbetrachter seiner Zeit der Vorstellung folgt, daß in der Nationalsprache das Weltbild eines ganzen Volkes niedergelegt ist, zum einen im Sinn einer bestimmenden Kraft des Volkscharakters, zum andern vorgestellt als Schöpfung „eines Volkstums“ (385).

[41] Pechau, Manfred: Nationalsozialismus und deutsche Sprache. Diss. Greifswald 1935.

Die Dissertation des Amtsleiters für Wissenschaft und Facherziehung ist die erste Studie über die „Sprache des Nationalsozialismus“. Er erkennt, daß Nazi-Wortschatz hauptsächlich aus alten und bekannten Wörtern mit neuem semantischen Gehalt besteht. In einer systematischen Betrachtung des nationalsozialistischen Wortschatzes werden „Ausdrücke der Parteiorganisation“ (13 ff.), „Kampfsprachformen“ (23 ff.) und „Sprachformen aus dem Kampf gegen das Judentum" (65ff.) untersucht. Der zweite Teil besteht aus wortgeschichtlichen Betrachtungen. Der aktive Nationalsozialist P. verweist ganz im Sinne Hitlers auf die Bedeutung des Propagandastils, d. h. eine allein auf Wirkung bedachte sprachliche Darbietung, die er als "Stil der Zweckmäßigkeit“ (96) bezeichnet.

[42] Probst, Friedrich: Volkstümliche Hochsprache - wie aber volkstümliche'Sprachlehre? In: Nationalsozialistisches Bildungswesen. 4. Jg. 1939, 230-236.

Vf. warnt vor einer Auf- bzw. Abwertung der ,volkstümlichen Hochsprache‘ oder Schriftsprache. Volkssprachlicher und schriftsprachlicher (bzw. hoch- oder, reichssprachlicher' [233]) Wortschatz seien miteinander verflochten, daher sei es Aufgabe einer volkstümlichen Sprachlehre, einen Ausgleich zu finden und beide so zu fördern, daß 
der Schüler beide Ausdrucksweisen beherrsche. Die Hochsprache ist für P. nur eine Stilart unter mehreren, die insgesamt die deutsche Sprache bilden. Die volkstümliche Sprachlehre sei „nicht bloß Lehre zur V. Hspr. [volkstümliche Hochsprache], sondern überhaupt Lehre zur Hochsprache, d. h. volkstümliche Lehre zur Hochsprache" (234).

[43] Rehm, Harald: Die Rede als Ausdruck politischer und künstlerischer Haltung. In: Nationalsozialistische Bibliographie. 1938, H. 9, I-VI.

Vf. zieht ästhetische Vergleiche zwischen Paulskirchenparlament und antikem Theater, zwischen Rhetorik, Kunst und Architektur. Im Gegensatz zur Rede, die zwar der Vorbereitung bedarf, jedoch „erst durch die Wirklichkeit des Augenblicks ihr Lebensrecht erlangt“" (III), durchlaufe das Kunstwerk einen langen Prozeß bis zur gültigen Ausgestaltung. In der Rede offenbare sich der Wille zur Erschaffung des Augenblicks, im Kunstwerk dagegen der Wille zur Beherrschung des Ewigen. Die „Ergriffenheit“ der Zuhörer von ,Führerreden“ zeige, „wie sich zwei tief in unserer Rasse begründete Willensrichtungen, der Wille zur Erfassung des Augenblicks und derjenige zur Beherrschung des Ewigen, gegenseitig durchdringen und steigern können“ (IV). Auch in „den Bauten des Führers" offenbare sich diese Synthese.

[44] Rehtmeyer, Viktor: Völkische Erneuerung und Sprachgestaltung. In: Muttersprache. 50. Jg. 1935, H. 9, $297-301$.

R. versucht, einen kausalen Zusammenhang zwischen nationalsozialistischer Umwälzung, völkischer Erneuerung und sprachlicher Umgestaltung zu konstruieren: „Dem aufmerksamen Beobachter des Sprachlebens war längst aufgefallen, daß sich in der Gebärde der Volkstumserneuerer auch eine neue sprachliche Haltung kundtat. Seitdem sie das gesamtdeutsche Leben beherrschen, werden allmählich die Grundzüge der sprachlichen Neugestaltung sichtbar" (298). Bei den Wissenschaften zeige sich dieser Prozeß etwa darin, daß Rassenkunde an die "Spitze aller Wissenschaften getreten" sei, daher hätten sich alle anderen Wissenschaften (auch die Sprachwissenschaft) dem Rassengrundsatz unterzuordnen. Die Folge davon werde ein allmählicher Umbau des „gesamten wissenschaftlichen Sprachgutes" (299) sein.

[45] Ruttke, Dr.: Sprachpflege, ein Erziehungsmittel zur Erb- und Rassenpflege. In: Muttersprache. 50. Jg. 1935, H. 11, 376-381.

Am Beispiel einer „,rassegerechten“ Rechtssprache stellt R. (geschäftsführender Direktor des Reichsausschusses für den Volksgesundheitsdienst) „Reinheit, Richtigkeit, Deutlichkeit, Schönheit und Volksverbundenheit" (378) als Maximen der Sprachpflege im nationalsozialistischen Staat auf. Für die „Erb- und Rassenpflege“ schlägt er eine Reihe von Begriffen vor, die Verbundenheit zwischen Volk und Rechtssprache herstellten, diese gefordert von dem ,gewaltigen Umbruch, den wir jetzt erleben“ (381).

[46] Schmidt-Rohr, Georg: MutterSprache. Vom Amt der Sprache bei der Volkwerdung. Jena 1933.

Nicht die Rasse, sondern das Volk ist die sprachbildende Kraft, und: „Volk ist Sprachvolk“ (VIII) - dies ist die von Schmidt-Rohr seiner Monografie zugrundegelegte Vorstellung. Mit den Kategorien ,Gemeinschaft' und ,Geist' werden unabhängig von einer rassistischen Unterfütterung die Beschaffenheit der verschiedenen Sprachen bzw. sprachliche Existenzformen erklärt. Dieser Sprachbegriff schafft dem Antisemiten Schmidt-Rohr die wissenschaftliche Voraussetzung dafür, Juden mit Deutsch als Muttersprache für Deutsche zu erklären: „Ob der Deutsche nordisch oder jüdisch oder ostisch, ob Städter oder Landmann, er wird im Auslande als Deutscher erkannt, was schon so manchen Juden erstaunen ließ, der unter dem Erziehungseinfluß des Antisemitismus unsicher wurde in der Frage, ob er ein Deutscher sei oder nicht" (210). Eine solche Auflösung rassischer Grenzen, welche die Gleichsetzung von deutsch und jüdisch ermöglicht, ist der Grund für die massiven Angriffe, die dieses Buch von der rassistischen 
Germanistik erfahren hat. Die Folge war Schmidt-Rohrs Kehrtwendung zum rassistischen Sprachbegriff seit Ende der 30er Jahre.

[47] Schmidt-Rohr, Georg: Rasse und Sprache. In: Muttersprache. 54. Jg. 1939, H. 9, $265-270$.

In diesem Aufsatz, in dem hauptsächlich das Verhältnis zwischen Rasse, Volk, Individuum und Sprache untersucht wird, geht S.-R. der Frage nach, wie weit Rasse und Sprache die Volkszugehörigkeit bestimmen. Für eine deutsche Volkszugehörigkeit sei eine von Blut und Rasse bestimmte Artung der Anlagen bzw. Begabungen, eine deutsche Weltanschauungsweise und die deutsche Muttersprache nötig. In der Rasse sieht S.-R. die „tiefste Wurzel der Sprache“. Die Sprache dagegen sei „die höchste Offenbarung der Rasse in der Geistwelt", daher sei Spracherhaltung mit Volkserhaltung gleichzusetzen.

[48] Schönbrunn, Walter: Die Sprache des deutschen Soldaten. In: Jahrbuch der deutschen Sprache. Bd. 1, 1941, 170-183.

S. unterteilt die Heeressprache in Kommandosprache und Kommißsprache („Kasernenhofblüten"). Beide Stilschichten werden anhand einiger Wortbeispiele veranschaulicht. Die Kommandosprache wurde von der militärischen Oberschicht im Generalstab geschaffen. Diese wiederum wurde von Clausewitz' und Moltkes Schriften beeinflußt, deren Vorläufer die militärischen Schriften Friedrichs des Großen gewesen seien. In dieser Tradition sieht S. die ,Dienstvorschriften', deren kurze und klare Hauptsätze er wegen ihrer „vorbildlichen Sprachschönheit“ (172) lobt. Vf. untersucht Komposita, die mit ihren altdeutschen Ausdrücken einen „fast feierlichen Klang“ (175) hätten. Dagegen stellten nicht zu vermeidende Abkürzungen in der Heeressprache eine Verarmung dar.

[49] Schultheiss, Tassilo: Sprachwissenschaft auf Schleichwegen. Berlin 1936.

Eine Sammlung rassistischer und antisemitischer Aufsätze und Zeitungsartikel des Verfassers aus den Jahren 1932 bis 1935, in polemischer Absicht geschrieben gegen Georg Schmidt-Rohrs ,MutterSprache“ (1933 [46]). Dieser habe das Judentum geschützt und den Rassenglauben des Nationalsozialismus verunglimpft, indem er versucht habe zu beweisen, daß durch die Kenntnis und Benutzung der deutschen Sprache während einiger Generationen aus Juden ein Untertypus des deutschen Volkes werden könne.

[50] Schulze, Werner: NSDAP. In: Muttersprache. 48. Jg. 1933, H. 10, 357-360.

S. schwankt in diesem „Überblick über die Namenwelt des Nationalsozialismus“ zwischen Lob und Kritik. Die nationalsozialistischen Bezeichnungen seien zwar „mit glücklicher Hand gefunden“ und gegen die „entwelschten“ Offiziersränge sei nichts einzuwenden, dennoch gebe es Mängel. S. kritisiert „verstaubte Namen“"wie Adjutant, Chef, Standarte und Generalinspekteur. Unverständlich ist ihm die Treue der Partei zu dem fremdländischen Ausdruck Propaganda. Er akzeptiert die Informationsökonomie der multisegmentalen Abkürzungen NSDAP, $S A$ und $S S$, gibt aber zu bedenken, daß dem Außenstehenden infolge des inflationären öffentlichen Gebrauchs dieser Kurzzeichen der eigentliche Wortsinn verlorengegangen sei.

[51] Schulze, Werner: Modewörter von heute. In: Jahrbuch der deutschen Sprache. Bd. 1, 1941, 66-71.

S. stellt fest, daß das von ihm 1934/35 in Wustmanns ,Sprachdummheiten " angefertigte Verzeichnis "der in Blüte stehenden Modewörter" (67) innerhalb von nur fünf Jahren veraltet sei. Er untersucht einige markante Modewörter der letzten Jahre, wobei er zwischen Ablehnung und Anerkennung schwankt. Zu den gegenwärtigen „Ausgeburten“ (68) gehöre das nichtssagende prima und das jugendliche pfundig. Andererseits spricht er von der „kraftvollen Ausdrucksweise unserer Jugend“ (69) und empfiehlt Mantheis Aufsatz ,Die Sprache der Hitlerjugend' (s. o. [34]). S. beklagt die zunehmende Entwertung ursprünglich sinnvoller Begriffe (Aktion) durch inflationären Gebrauch. Beispiels- 
weise sei das Hochwertwort Einsatzbereitschaft in Gefahr, „abgegriffen zu werden von den vielen Fingern der Menge" (71).

[52] Seemann, Horst: Die Sprache der Wissenschaft. In: Nationalsozialistisches Bildungswesen. 6. Jg. 1941, 195-197.

Eine Mischung aus funktiolektaler (Wissenschaftssprache), soziolektaler (Studentensprache) und puristischer Sprachuntersuchung. S. fordert eine anschauliche, klare, allgemein verständliche Wissenschaftssprache, „volkstümlich und lebenswarm“ (196), denn die Wissenschaft, die im Dienst des Volkes stehe, solle auch vom Volk verstanden werden. Allgemein verständlicher Stil heißt für S. „fremdwortfreies Deutsch“ (196). Es werden „Fremdwortungeheuer“ (196) und Musterbeispiele „gute[r] Verdeutschungen in der Wissenschaftssprache“ (197) angeführt. S. konstatiert eine zunehmende Säuberung der Studenten- bzw. Hochschulsprache. Im Bereich der Politik läßt S. solche Ausnahmen gelten, die sich der Verdeutschung aufgrund der „Zwischenstaatlichen Verflechtung“ entzögen (Nation, Politik, Propaganda).

[53] Soenke, Jürgen: Wiedergeburt der Rede. In: Nationalsozialistische Bibliographie. 1938, H. 9, VII-XII.

S. skizziert vom Mittelalter ausgehend die geschichtliche Entwicklung der Rhetorik. Er ist begeistert von der ,gottbegnadeten rednerischen Begabung Luthers" (VIII), er lobt die „bezwingende Kraft seines Wortes“ (VIII), seine volkstümliche Art und „kämpferische Haltung“ (VIII), er verurteilt die Parlamentsrede des unpolitischen „Diskussionsredners" (IX) im 19. Jh. und verdammt die rednerische Routine jüdisch-marxistischer Demagogen und Agitatoren. Der Nationalsozialismus habe die Wiedergeburt der Rede ermöglicht. Schöpfer der nationalsozialistischen Rede sei Adolf Hitler, der die deutsche Sprache zur Weltsprache erhebe. Wie alle politischen Strategen hält S. die Rede für eines der wichtigsten Mittel der politischen Gestaltung im Nationalsozialismus.

[54] Sommer, Paul: Erläuterungen zu Adolf Hitlers ,Mein Kampf. Leipzig 1933.

Die „Erläuterungen“ bestehen fast ausschließlich aus der Übersetzung der von Hitler in ,Mein Kampf verwendeten Fremdwörter (vgl. Köpke [26]).

[55] Steche, Theodor: Volk, Nation, Rasse und Sprache. In: Völkische Kultur 1, 1933, $228-230$.

S. greift das 1932 erschienene Buch ,Die Sprache als Bildnerin der Völker' (2. Aufl. 1933 u. d. T. ,MutterSprache‘ [46]) von Georg Schmidt-Rohr an. Er wirft Schmidt-Rohr vor, die Begriffe ,Nation' und, Volk' zu vermischen und behauptet, Schmidt-Rohr untergrabe die Rassenfrage. Dessen Denkfehler liege in der Annahme, daß die Sprache die einzige Grundlage des Volkstums sei. Zur rassischen „Wesensgemeinschaft“",Volk' (im Gegensatz zur „Willensgemeinschaft“ [228], Nation') gehöre jedoch „dieselbe Sprache und dieselbe Rasse“ (229). S. warnt vor einer Zersetzung der Rassenfrage und damit eines „Teil[s] der nationalsozialistischen Weltanschauung“ (230) durch „einseitige Ausdeutung wissenschaftlicher Forschungsergebnisse" (230).

[56] Steche, Theodor: Soziale Wirkungen des Sprachgebrauchs. In: Völkische Kultur, Februar 1934, $91-93$.

Die „Überwindung des Gegensatzes zwischen Handarbeitern und Kopfarbeitern“ (91) ist auf sprachlichem Gebiet zu leisten durch das Bemühen der ,Kopfarbeiter", einfaches und jedem verständliches Deutsch zu sprechen, d. h. „möglichst kurze Sätze bauen und möglichst wenig Fremdwörter gebrauchen“. Denn: „Fremdwörter sind Standesdünkel - halte dich möglichst frei davon!“ (93).

[57] Stegmann von Pritzwald, Kurt: Die erzieherisch-politische Position der Sprachwissenschaft. In: Volk im Werden. 4. Jg. 1936, 196-208.

S. legt dar, daß Wissenschaft, und damit auch Sprachwissenschaft, nicht mehr ein lebensfernes Dasein friste, sondern dem Sprachwissenschaftler täglich „Fragen der 
Wirklichkeit" (197) vorgelegt würden. Dies begründe die pädagogisch-politische Einsatzmöglichkeit der Sprachwissenschaft. Dem „pädagogischen Konzentrationsgedanken" (199) folgend bedeute dies die Behandlung desselben Gegenstands aus der Sicht verschiedener Unterrichtsfächer. S. sieht darin die Vergegenwärtigung des neuen Ganzheitsgedankens. Am Beispiel sprachhistorischer Prozesse im Zuge der Christianisierung wird dieses Konzept der Konzentration veranschaulicht, denn die „Germanisierung des Christentums gibt dem Unterricht bei sprachwissenschaftlicher Interpretation besonders zahlreiche Beispiele, um die völkische Umprägung erzieherisch einprägsam darzustellen“ (202). S. stellt damit „unterrichtliche Pflege der deutschen Hochsprache [als] Dienst am Reichsgedanken“ dar (204). Sprachwissenschaft erscheint in diesem Beitrag als Zentrum nicht nur der Erkenntnis, sondern der völkischen Frage schlechthin, der „volksdeutsche Grenzlandkampf [ist] in vorderster Linie ein Sprachkampf" (197). Die Bindung des Sprachwissenschaftlers ist danach existenziell: „Die Unübertragbarkeit des sprachlichvölkischen Gesamtplanes fordert Unübertragbarkeit der in ihm angelegten Lebensformen der Völker, fordert Kampf für die Eigenständigkeit der Völker, ein Einsatz, so eindrucksvoll und überzeugend, $\mathrm{da} B$ er wohl ein Sprachwissenschaftlerleben wert ist" (205). Den - unvermeidlichen - Übergang zur Ideologie des Nationalsozialismus findet Vf., wenn er die Empfänglichkeit der Deutschen für den Führergedanken ,sprachwissenschaftlich ' dartut und ,in seiner Repräsentation die Verwirklichung einer verschütteten uralten Herrschaftsauffassung “ (206) erkennt. Solche Affinitäten, solch ein Fortleben der „Volksseele“ (296) historisch zu erklären, sei Aufgabe des Sprachwissenschaftlers.

[58] Stroh, Fritz: Der volkhafte Sprachbegriff. Halle 1933.

Diese Monografie ist eine Zusammenstellung der die ideologische Germanistik der NaziZeit beeinflussenden wissenschaftlichen Strömungen. Herder, Humboldt (die geistigen Väter der ,Deutschen Bewegung'), Voßler, Weisgerber - entsprechend ,Sprache und Gemeinschaft', ,Sprache als Volksbildnerin', ,Volk als Sprachbildnerin', ,Sprache, Geist, Volk' sind die bis zum Überdruß von der völkisch-nationalsozialistischen Germanistik erfaßten Namen und Themen, um die auch dieses Buch kreist. Dementsprechend verwirft Stroh das positivistische Denken, die „materialistisch entartete Sprachauffassung“ (1) und die historisch-vergleichende Sprachwissenschaft.

[59] Wachler, Max: Die Wiedergeburt der deutschen Rechtssprache. In: Jahrbuch der deutschen Sprache. Bd. 2, 1944, 194-198.

W. fordert eine einprägsame, auf die breite Volksschicht zugeschnittene Rechtssprache. Alle überflüssigen Fachwörter und vor allem Fachfremdwörter der veralteten Amtsund Kanzleisprache, ihr verschachtelter Satzbau, die Weitschweifigkeit und „blutleeren Wörter“ der „Papiersprache“ (197) sollten beseitigt und es sollte ein einheitlicher Sprachstil des Rechts geschaffen werden, „kernig, bildkräftig und sinnvoll“.

[60] Wagner, Hans: Taschenwörterbuch des Nationalsozialismus. Leipzig 1934.

Von Abrüstung bis Zwölfter November 1933 soll die Darstellung nationalsozialistischer Begriffe und Namen „mithelfen an der vom Führer gestellten Aufgabe ,der Erziehung des deutschen Menschen zum Bürger dieses neuen Staates“ “ - so in dem vom „Reichsfachberater für staatsbürgerliche Erziehung im N[ational]S[ozialistischen]L[ehrer]B[und]" Wallowitz verfaßten Geleitwort. Den Begriffserläuterungen sind z. T. Abbildungen beigefügt. Diese Enzyklopädie des Nationalsozialismus mag zwei verschiedene Aufgaben zu erfüllen gehabt haben: einerseits wirklich Erklärungsbedürftiges der komplexen undurchsichtigen Nazi-Organisation beschreiben - dies sicher nur so weit, wie Volksaufklärung den Herrschaftsapparat nicht gefährdete. Andererseits - dies die wesentliche staatstragende Funktion - die Welt des Nationalsozialismus so zu vermitteln, daß er als organisatorisch straff gegliedertes (Amt für Beamte bei der Reichsleitung 
der Partei), politisch anerkanntes (Auswärtiges Amt), programmatisch fundiertes (Autarkie), soziales (Bedarfsdeckungsscheine) Gemeinwesen erscheint.

[61] Weisgerber, Leo: Die Haltung der Deutschen zu ihrer Sprache. In: Zeitschrift für Deutschwissenschaft und Deutschunterricht, 1943, H. 1. 12-18.

Die Deutschen leben traditionell in der „Überzeugung von der volkhaften Kraft der Muttersprache“ (17) - u. a. Herder, Humboldt, J. Grimm, Fichte ruft Weisgerber wie alle Sprachbetrachter seiner Zeit als Gewährsleute seiner bekannten Ansicht auf, die mutatis mutandis sein gesamtes Werk durchzieht. Etymologisch belegt er sie mit der Form- und Bedeutungsgeschichte des Wortes Muttersprache, welches die „stark gefühlsmäßige Bindung [der germanischen Völker] an die Sprache“ (16) dokumentiere. Insofern die deutsche Sprache eine Entwicklung genommen habe hin zu einer immer weiter sich ausbreitenden Weltsprache, „ergibt sich daraus eine ungeheuer verantwortungsvolle Aufgabe, deren Tragweite erst kürzlich beleuchtet wurde durch den Erlaß des Führers über die Deutsche Akademie und ihre sprachlichen Aufgaben“ (18). Ziel eines verantwortungsbewußten Sprachgebrauchs: „das ewige Volk und Reich der Deutschen“ (18).

\section{Einordnung und Bewertung}

\subsection{Selbstverständnis}

Die „Leistung“ der ideologischen Germanistik liegt darin, daß sie sich unter den Bedingungen des Nationalsozialismus in eine theoretische und methodische Tradition stellt, die sie zwingt, sich fortwährend zu definieren. Sie bedarf dieser Vergewisserungsstrategien, um sich und ihren neuen Zweck glaubhaft zu präsentieren. Dieser heißt: Empfehlung des Fachs, Andienen seiner Kenntnisse. Er bedeutet: Wissenschaftliche Tradition reduzieren zu einem außerhalb der Wissenschaft liegenden Zweck, Sinngebung wird Maxime: „,bewußt ,sinnfreie‘, ,voraussetzungslose“ Wissenschaft scheint mir von einem geschärften wissenschaftlichen Ehrgefühl durchaus nur eine Wissenschaft niederen Grades zu sein gegenüber derjenigen, die ihr ,Streben" nach einem Sinn ausrichtet" [46, XII] - der heißt von 1933 an Machterhaltung des nationalsozialistischen Regimes. Wenn er verbrämt werden soll, dann definiert sich Sprachwissenschaft über den Zweck der Volksnähe. Solche Germanistik verstand sich in diesem Sinn als populäre Wissenschaft (,Leitfadenlinguistik werden wir sie unten nennen) und sah in einer solchen Volksnähe eines ihrer höchsten Ziele: „Vertiefung der nationalen Arbeit“ und „Besinnung auf das volksorganisch Notwendende" bedeutet etwa Schmidt-Rohr ",volksverantwortlich gebunden“ zu sein“ [ebd. VIII]. Politisierung der Profession erscheint damit als Merkmal, das als inhärenter Wesenszug verstanden wird: „Sprachwissenschaft ist politische Wissenschaft im weiteren Sinne, $[\ldots]$ : wenn sie die für das Ganze lebenswichtigen und zukunftsträchtigen Kräfte im Gegenwärtigen und im Vergangenen sinnvoll zu deuten und für zukünftige Gestaltung und Erfüllung zu entbinden vermag“ $[58,76]$. Von dieser Selbstaufgabe ist es zum nationalsozialistischen Bekenntnis nur ein kleiner Schritt: „den Kernstaat in Ordnung [...] bringen [und] an dem größeren Deutschland der Zukunft [...] bauen“ - Schmidt-Rohr gibt Hitler mit seinem Sprachbuch „eine Waffe [in die Hand] für dieses große heilige Werk“ [46, IX f.]. Insofern der National- 
sozialismus sich als ,dynamische Bewegung' verstand, erklärt sich in diesem Zusammenhang aktionistische Sprachgermanistik, die sich als ,Wissenschaft der Tat' versteht, den Begriff der Wissenschaft aufgebend, den der Tat akzentuierend: „wir tauschen sie [Sprachkritik] gern gegen ein sicheres Wissen um unsere Berufung ein, gegen die genauere Erkenntnis unseres Lebensfeldes. Wir wissen, da $\beta$ es hier nicht gilt, ein Schicksal zu erleiden, sondern zu erfüllen; daß tausend Gedanken auf Erlösung warten [...] durch uns; daß tausend Taten der Erfüllung harren [...] durch uns" [ebd. 132]. Aus einem solchen Selbstverständnis resultiert weiterhin eine so unspezifische wie unwissenschaftliche Zielbestimmung der Profession, wie sie Schmidt-Rohr in seiner ,MutterSprache“ gibt: „Was wir brauchen ist die einheitliche Formung eines geistigen Typus, der immer vollkommener, entschlossener, heroischer, deutschbewußter wird. Wir brauchen Menschen mit sicheren deutschen Lebensformen, männliche Männer und weibliche Frauen. Wir brauchen Menschen, die durch ihre Lebensform in der ganzen Welt erhaltend und werbend für unsere Kultur wirken“" [ebd. VII]. Der Wissenschaftler erfüllt diese Aufgabe und erscheint somit als Dienstleistender, der „keine Wissenschaft mehr um der Wissenschaft willen, sondern zum Besten seines Volkes treibt" [52, 195].

Diese Selbstsicht hat Folgen: für die Haltung gegenüber dem wissenschaftlichen Gegenstand und für den Stil der Darstellung.

\subsubsection{Byzantinische Germanistik oder wie man sich andient}

Die Spracharbeit der ideologisierten Germanistik dient mehr oder weniger ausschließlich und mehr oder weniger unverblümt der machterhaltenden Reproduktion des Nationalsozialismus.

Am unverhohlensten arbeitet so byzantinische Germanistik. Sie hat vorzugsweise die Sprache Hitlers zum Gegenstand: „Wenn jeder Leser das Buch "Mein Kampf um seines Inhalts willen für das wichtigste Buch erklären muß, das uns in neuester Zeit geschenkt worden ist, so wird er auch die Sprache, in der es geschrieben ist, bewundern müssen, und es muß uns auch eine Betrachtung dieser Sprache fesseln [...] die Sprache A. Hitlers ist [...] klar und verständlich [...] Er verfügt über einen schier unerschöpflichen Wortschatz, der seinem Gedanken immer den treffenden Ausdruck leiht" [38, 2]; aus Kindt, ,Der Führer als Redner': „In diesen sachlich darlegenden Partien spürt man das unterirdische Brodeln der Lava der Leidenschaft, die mit ungeheurer Vehemenz dann in der eigentlichen Argumentation herausgeschleudert wird. Hitlers Reden haben alle den Start des Flugzeuges“ [24, 13]; Hitler als Verkünder einer göttlichen Botschaft: ,einer ist unter uns, der gleichsam stellvertretend für uns alle hört. Er hört die Weisungen, die der Weltgeist in diesem Augenblick der deutschen Nation erteilt, und gibt sie weiter an die Millionen, die an seinen Lippen hängen. Deutschland hat wieder einen Propheten [...] ein Ereignis, dessen Betrachtung uns den letzten geschichtsphilosophischen Sinn der nationalsozialistischen Revolution enträtseln kann" [ebd. 5], durchaus 
mit partiell zutreffender Schlußfolgerung: „Das Dritte Reich ist heraufgeführt worden [...] allein durch das Wort des Führers [...] Hitler hat buchstäblich das deutsche Volk in den neuen Staat hineingepredigt" [ebd. 7]; Hitler als Nachfolger der antiken Rhetoren: „Das Wunder, das wir und mit uns die Welt an Adolf Hitler erlebt haben und noch erleben, begann mit der ihm verliehenen Gabe der Rede. Durch sie machte er möglich, was dem größten Redner des Altertums, Demosthenes, trotz aller Kunst und Macht seiner Rede nicht gelang: Sein Volk vor dem Untergang zu bewahren“ $[38,1]$. Diese Idolatrie bedeutet zugleich und konsequent Unantastbarkeit - Hitlers Sprachdeuter konnten der Rüge seiner Knechte sicher sein: ,die Auslegung von Führerworten [...] ist natürlich vollständig abzulehnen, denn es ist untragbar, daß Unberufene versuchen, Worte des Führers auszudeuten. Im übrigen ist der Führer in seinen Äußerungen so klar, daß auf ,Auslegungen“ verzichtet werden kann" [26, III f.]. Dieser Zorn richtet sich gegen denjenigen, der sich im Dienen verliert: „In seiner vielseitig fesselnden Art ist dieses Werk nach Form, Aufbau, Planung und Gehalt ein klassisches Meisterwerk. Deshalb ist Hitlers ,Mein Kampf auch hier erläutert worden. Die reifere Jugend soll in das Verständnis dieser neuen Volksbibel eingeführt und mit den darin dargelegten und meisterhaft geführten Aufbaulinien aufs beste vertraut gemacht werden. Der Erwachsene aber soll durch das aufmerksame Lesen dieses Werkes seinen nationalen Bürgersinn läutern, schärfen und tüchtigen und als Hausvater die darin niedergelegten Gedanken seiner Familie einprägen, jedes Glied befähigend, diese zum Heile und Glücke des Ganzen in bedeutsam gestaltende Tat um- und auszuprägen“ $[54,7]$.

\subsubsection{Sprachideale und ihre Funktion}

Der machterhaltenden Reproduktion des Nationalsozialismus dient weiterhin - den Schein wissenschaftlicher Sprachbetrachtung eher wahrend das Thema ,Krieg und Sprache'. Im Sinn solch einer politisch funktionalisierten Linguistik ist ein Beitrag wie Matschoß, ,Der Einfluß des Weltkriegs auf die Sprache' [36], zu beschreiben. Die Linguistik vermag zur systematisch betriebenen Vorbereitung des zweiten Weltkriegs einen sprachhistorischen Beitrag zu leisten, indem sie Wortschöpfungen des Ersten Weltkriegs nachspürt und als „sprachschöpferische Leistung“ [ebd. 451], als „frische Ausdrücke“, durch die das Hochdeutsche „wieder farbiger wird“ [ebd. 453], kommentiert. Kriegstreiberei vor allem aber bedeuten Formulierungen wie „ein zukünftiger Krieg wird vermutlich dieses seltsame Wörterbuch noch durch neue Sinneseindrücke ergänzen helfen. Schon jetzt ein Beispiel von Bombeneinschlägen“ [ebd. 452], „der ,Zukunftskrieg“ wirft schon sprachlich seine Schatten [voraus]" [ebd. 455]. Ähnlich ist der Beitrag Lindens, Wehrhafte Sprache` [31] zu beschreiben. Im ersten Kriegsjahr verfaßt, erscheint diese Darbietung als Kriegsverherrlichung und damit Rechtfertigung im linguistischen Gewand: „Man vergleiche den in der Wucht und Klangkraft seiner knapperlesenen Worte unvergleichlichen 
Sammelbericht über die Taten der deutschen Luftwaffe im polnischen Feldzuge: ,An diesen schnellen und großen Erfolgen hat die Luftwaffe wieder entscheidenden Anteil [...] Marschkolonnen wurden zersprengt, Rückzugswege durch Zerstören von Brücken und Übergängen versperrt, Versuche von Gegenangriffen schon in der Bereitstellung zerschlagen [... $]^{\star}$ Man wird nicht verkennen, $\mathrm{da} ß$ in diesen eindrucksvollen Satzgebilden ein außergewöhnlicher künstlerischer Sinn gewaltet, durch Wortwahl und klangliche Abstufung der Satzglieder die machtvollste Wirkung herausgeholt hat, ohne einen Augenblick das Gesetz der Schlichtheit und unbedingten Wahrhaftigkeit zu verletzen" [ebd. 131]. Während des Krieges leistet Nazi-Germanistik, wie etwa der Philologe Götze im Kriegsjahr 1941, ihren Beitrag an der sprachwissenschaftlichen Heimatfront: „Nicht nur Deutsche kämpfen gegen Engländer und Franzosen, auch Deutsch kämpft gegen Englisch und Französisch“ [15, 20]. Erwartungsgemäß erscheint der Krieg als eine produktive Sprachkraft: ,[Der Krieg] lenkt die Phantasie, auch die sprachliche, in gesunde Bahn, leiht ihr leuchtkräftige Bilder, befreit sie von des Gedankens Blässe und zwingt sie, sinnlich klar bei einfachen, überzeugenden Anschauungen zu bleiben" [ebd. 25]. Wie läßt sich die Verstiegenheit heute fassen, die zwischen Militarismus, Nationalismus und Sprache begeistert zu vermitteln sich bemüht?: „Namentlich alle neue Entwicklung der letzten Jahre ist von vornherein und bewußt deutsche Wege gegangen, und gerade die jüngsten Waffen, die uns immer wieder so viel Freude bereiten, Panzer, Unterseeboot und Flugzeug, sind auch sprachlich Glanzleistungen einer im Aufstieg begriffenen rein deutschen Welt" [ebd. 32]. Kriegssprache wird glorifiziert, indem das Dichterwort beschworen wird diese Entpoetisierung von Literatursprache läßt den martialisch geprägten Literaturbegriff des Nationalsozialismus erkennen: „Das deutsche Wort ist durch ihn [den Krieg] viel kraftvoller und bewußter, wuchtiger und freier geworden. Ein Deutsch, wie es der Führer in seinen Reden, wie es unsre Heeresleitung in ihren Tagesberichten erklingen läßt, in Erz geschrieben und doch von einem Wohlklang, daß es der Dichter Wort für Wort in seine Lieder aufnehmen könnte“ [ebd. 33]. Die Funktion, Verhinderung von Kriegsmüdigkeit" ist offensichtlich: „[Dienstvorschriften] spiegeln den Geist des deutschen Heeres in seiner weltweiten Überlegenheit wider. Bewunderungswürdig und vorbildlich ist die Klarheit und Knappheit jedes Satzes“ [48, 173].

Soldatensprache aber ist noch mehr. Sie wird als sprachlicher Ausdruck einer dem Nationalsozialismus idealen Existenzform bewertet ${ }^{5}$ : „Wie seine Sprache, so ist auch er [der soldatische Führer]: gerafft und zuchtvoll, klar und bestimmt, schlicht und schweigsam" [29, 168]; der Grund dieser Hoch-

${ }^{5}$ In diesem Sinn positiv besetzt ist außerdem, der Soldatensprache vergleichbar, die Sprache des Sports: „Eine Stellungnahme zu der Versportung unserer Sprache setzt eine eindeutige Einstellung zum Sport selbst voraus, die im Sinne des Nationalsozialismus nur bejahend sein kann“ $[5,96]$, entsprechend bedeutet „Versportung eine Blutauffrischung der Sprache“ [ebd. 98; vgl. außerdem 36 und 38]. 
achtung: „Da für unsere Zukunft der heldische und kämpferische Mensch als Erziehungsziel gilt, muß auch die Sprache soldatisch sein. Unsere Sprechweise muß kernig, hart, straff, klar, bündig und wirksam werden" [1,141]. Und obwohl bekannt, ist das unverhohlene Bekenntnis zu den kriegerischen Ambitionen des Nationalsozialismus immer aufs Neue erschreckend: „Die Sprache des Soldaten ist im Gesamtleben unseres Volkes eine so bedeutende Macht, daß sie weit hinaus über die Rolle einer bloßen Standessprache geradezu einen erziehlichen Einfluß auf die Ausdrucksweise und damit auf die Haltung und die Denkzucht beinahe jedes einzelnen Volksgenossen ausübt“ $[48,170]$. Hierzu zählt auch die Analyse der kommunikativen Urform nationalsozialistischen Sprachhandelns: „Meldung und Befehl sind zwei Grundtatsachen jeder bestehenden Sozialordnung [...] Das Volk [...] in seinem Lebenskampfe kann nur auf das Wort hören, das ihm Schicksal bedeutet. Schicksal aber liegt in Meldung und Befehl. Nur diese beiden dichterischen Grundhaltungen kann es für sein Dasein als notwendig und siegverheißend anerkennen. Alles andere ist entbehrlich, wenn nicht schädlich, und muß dann ausgeschieden werden, damit es der Mannschaft den Blick ins Kampffeld nicht vernebelt" [11, $374 \mathrm{ff}$.]. Man konstruiert eine beliebige Traditionslinie, ignoriert dabei Geschichte und greift willkürlich Passendes heraus: „Die Lyrik der Freiheitskriege war Meldung der jungen Frontkämpfer. Doch neben ihnen stand auch ein ergrauter Feuerkopf: Ernst Moritz Arndt, der einzige, dem mit dem Bilde eines neuen Reiches die beschwörende dichterische Befehlsgewalt gegeben war: ,Das ganze Deutschland soll es sein!' [...] Als Dichtermund verstummen mußte, übernahm der politische Soldat Adolf Hitler die Befehlsgewalt" [ebd. 376].

Soldatensprache also - das können wir sehen und niemanden wird es verwundern - ist die am meisten geschätzte sprachliche Existenzform, sie entsprach zuallererst nationalsozialistischem Weltbild: „Das Dritte Reich ist im Begriff, neben seiner kriegerischen auch der arbeitenden Mannschaft dies Wort im umfassenden Sinne genommen - die Zucht der Meldung und des Befehls einzusenken. Die neue Sozialordnung ist die Deutsche Arbeitsfront" [ebd. 375]. Soldatensprache dient so als Maßstab. Kanzleisprache „Die Langatmigkeit und Verschachtelung der Kanzleisprache gedeiht nicht in der frischen Luft des Feldlebens. Für die Phrase ist kein Platz" [29, 168] und Wissenschaftssprache der Intellektuellen - „die Sprache des deutschen Soldaten ist diese [Wissenschafts-]Sprache bestimmt nicht!“ $[52,196]$ - sind die Ziele der Abwertung.

Intellektuellen- bzw. Wissenschaftssprache ist das Gegenstück zur volksnahen Sprache und darum abzulehnen - das Sprachurteil erledigt die Diskriminierung des verachteten Geistes gleich mit: „So erklärt sich aus dem unbeteiligen Abseitsstehen von den Vorgängen beim Intellektuellen seine Spracharmut der farblosen Begriffe. Ebenso erklärt sich aus seinem gewollten Unbeteiligtsein eine gewisse Standpunktlosigkeit (,Objektivität') der gesamten Darstellung. Beides[!] [...] erklären die mangelnde Einwirkung und geringe Überzeugungskraft der Intellektuellen-Hochsprache gegenüber der volkstüm- 
lichen Hochsprache“ [30, 84]. Intellektuellensprache ist schlechte Sprache katexochen - „sprachliche Starrheit und Bewegungsarmut des Intellektuellen“ [ebd.] -, Volkssprache dagegen sprachliches Ideal schlechthin: „Was die Schriftsprache in der Wiedergabe der Gedanken und Begriffe voraus hat, gleicht die Volkssprache mit ihrer Leistung, d. h. mit der anschaulichen Wiedergabe von Vorstellungen mehr als genügend aus; ihr Wortschatz ist zwar geringer, dafür aber überwiegend anschaulich, bildhaft und redensartlich, der Satzbau aufzählend, beiordnend“ [42, 231], der Grund: „Volkstümliches Sprachdenken ist gekennzeichnet durch die Nähe zum Gegenstand, durch die Berührung und Anrede des Gegenstandes, mit dem man sozusagen ,auf Du

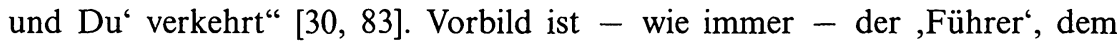
zudem die historisch verbürgte Größe Luthers beigesellt wird: „Auch er [Hitler] spricht [wie Luther] wieder eine Sprache, die alle verstehen, ja, die alle in ihren Bann zwingt. Die Kraft seiner Bilder und Begriffe, gepaart mit einer monumentalen Einfachheit[!], erobert die Herzen der verstocktesten Gegner. [...] Dabei scheint gerade in der leichten Dialektfärbung seiner Rede eines der Geheimnisse ihrer Volkstümlichkeit zu liegen“" [53, XI].

Solche idealisierende Überhöhung volksnahen Sprechens kulminiert im Mythos der Muttersprache. Mit ihr als wissenschaftlichem Gegenstand kommt linientreue Germanistik der Nazizeit zur Bekenntniswissenschaft herunter, dokumentiert sich ihr auf Ideologie gegründetes Wesen: „Der Begriff der Muttersprache [läßt sich] nur durch das Verhältnis von Sprache und Gemeinschaft, von Sprache und Volk bestimmen" [58, 51]. Dies zwar bereits seit der Reichsgründung, insofern sich aber der Begriff wie kaum ein anderer beschreibungssprachlicher Terminus „nationalistisch und chauvinistisch“ (Ahlzweig 1989,50 ) besetzen läßt, kann er „bruchlos vom Faschismus eingesetzt werden“ (ebd.): „Durch die ganze deutsche Geschichte hindurch finden wir die Muttersprache in erster Linie gespürt als volktragende und volkerhaltende Macht. Es ist eine Haltung, die wir im Grunde bereits vorgezeichnet sehen in dem kennzeichnend germanistischen Begriff Muttersprache, jenem Wort, das wir zu frühest im altnordischen moðurmál antreffen, und das die Muttersprache gleich dem Mutterboden und dem Mutterland einordnet unter die zeitlos waltenden Grundkräfte des volklichen Lebens. Alle germanischen Völker zeigen diese Einschätzung der eigenen Sprache und bekennen dadurch eine stark gefühlsmäßige Bindung an die Sprache, die gleich einer Mutter im Leben des Volkes und jedes einzelnen darinsteht" $[61,16]^{6}$. ,Schicksal" ist auch hier Zentralbegriff: „Unsere Muttersprache ist das große uns tragende geistig-seelische Schicksal“" $[46,129]$.

6 An dieser Stelle ein Wort zum Fall Leo Weisgerber und seine Schonung seitens der Nachkriegsgermanistik. Sie scheint unverständlich. Kann diese 1943 gehaltene Rede noch Zweifel an der Affinität ihres Verfassers zum Nationalsozialismus (so etwa Römer 1985, 163 f.) bestehen lassen? Anlaß - „Festrede zur Feier der Reichsgründung und der nationalen Erhebung am 30. Januar 1943“ - , Zeitpunkt - zwei Jahre 


\subsubsection{Leitfadenlinguistik}

Andere machterhaltende Beiträge erfüllen ihre Funktion weniger vordergründig. ,Leitfadenlinguistik “ wird in solchen Arbeiten betrieben, in denen zur Täuschung des Volkes spracherzieherische Entwürfe präsentiert werden: „Da der Sprachlehre nun auch einmal eine Aufgabe, heute als Sprachgestaltung sogar eine sehr wesentliche Aufgabe in der Spracherziehung zufällt, muß die Frage nach der volkstümlichen Sprachlehre gestellt werden“ $[42,230]$. Die Konkretheit solch spracherzieherischer Ambitionen ${ }^{7}$ zeigt sich z. B. in der ,administrativen“ Integration: „Gerade zu diesem Zeitpunkt, wo die Reichswaltung des NS-Lehrerbundes sich anschickt, eine zielbewußte Erziehung zur kraftvollen deutschen Hochsprache bei Lehrern und Schülern zu beginnen, muß man sich über das Wesen der zu erstrebenden Hochsprache [i. e. „volkstümliche Hochsprache"] klar sein" [30, 83]. Die Fachsprache des Rechts erscheint in diesem Zusammenhang als ergiebiger Forschungsgegenstand, Volksnähe zu verwirklichen: „Es muß [...] ein Ausgleich zwischen den Forderungen der Genauigkeit und der Volkstümlichkeit [in der Rechtssprache] gefunden werden“ $[59,196]$; ebenso die Sprache der Wissenschaft: „Will man [...] eine entscheidende Sprachpflege treiben, so muß man sich vor allem einer Sprachmacht zuwenden, die zweifellos zu den größten gehört, der Sprache der Wissenschaft" $[52,195]$ sowie das Amtsdeutsch [vgl. 10; 22]. Auch die beiden zeitgenössischen Wörterbücher [17; 60] gehören in diesen Zusammenhang. ,Leitfadenlinguistik' ist Ausdruck nationalsozialistischer Popularisierungsbestrebungen. Sie ist als Form politisierter Linguistik auf den Sprachbenutzer gerichtet, dem als Laien Sprachwissenschaft im praktischen Sinn nahegebracht

vor Kriegsende, als Goebbels den ,totalen Krieg‘ ausruft, der Rußlandfeldzug scheitert, die Verfolgung von Juden nicht mehr übersehbar ist und das Ansehen Deutschlands in der Welt einen Tiefstand erreicht - sowie Inhalt eben dieser Rede sind nationalsozialistisches Bekenntnis: „Wenn schon die deutsche Haltung zur Sprache auch in die Entscheidungen unserer Tage eingegangen ist, dann müssen wir wissen, $\mathrm{da} ß$ zwei Dinge wesentlich davon abhängen: die geistige Geschlossenheit des deutschen Volkes und die weltweite[!] Wirkung des deutschen Geistes. An jedem von uns ist es, sein Handeln danach zu gestalten. Der Weg ist der der täglichen Bewährung in scheinbar kleinen Dingen. Das Ziel aber ist dasselbe, das uns bei dem Gedenken an den 18. Januar 1871 und den 30. Januar 1933 immer leuchtender vor Augen tritt und das die Quelle unserer sieghaften Kraft im jetzigen Entscheidungskampfe [ist]: das ewige Volk und Reich der Deutschen" [ebd. 18]. Weisgerbers Leugnen mu $B$ vor dem Hintergrund und Inhalt seiner Veröffentlichungen abgewiesen werden. Gerd Simon hat sich mit Weisgerber, zumal mit seiner Tätigkeit als Zensuroffizier in Rennes während des zweiten Weltkriegs, beschäftigt: „Was die Auseinandersetzung mit Weisgerber freilich schwer macht, ist der Umstand, daß er sein Engagement für die damaligen Machthaber heute nicht nur leugnet, sondern sich sogar als Widerstandskämpfer hinstellt. In seinen Augen war seine Sprachwissenschaft [...] als Gegensatz zum Nationalsozialismus konzipiert“ (1982, $36 \mathrm{f}$.) - schwer zu glauben angesichts der oben zitierten Rede.

7 Zum Zusammenhang zwischen Sprecherziehung und Rassismus vgl. R. Römer (1985, 146). 
werden soll. Sie ist vor allem aber, wie keine andere Teildisziplin des Fachs, geeignet, die beiden nationalsozialistischen Handlungsziele Krieg und Judenverfolgung scheinwissenschaftlich $\mathrm{zu}$ fundieren und damit weniger zu legitimieren (der Nationalsozialismus war darauf nicht angewiesen), als vielmehr potentieller populärer Kritik zu entziehen und damit zu tabuisieren, auf die distanzschaffende Aura der Wissenschaftlichkeit setzend.

Wir sehen: Die Sprache Hitlers, Kriegs- und Soldatensprache, Volkssprache und die erwähnten Aspekte der ,Leitfadenlinguistik' sind Arbeitsbereiche nazi-naher Germanistik. Ihre prominenten Vertreter sind z. T. bekannt (Götze, Stroh, Panzer, Weisgerber, vielleicht auch Geißler), viele müssen als Laienlinguisten gelten. Was sie und ihre Arbeiten disqualifiziert: Sie waren nicht gezwungen - etwa zum Schutz der eigenen Existenz oder auch nur zur Schaffung von Freiräumen, in denen ungestört gearbeitet werden konnte - , sich in dieser Weise zu profilieren. Sie taten es nicht nur freiwillig, sondern auch bekenntnishaft - intentional und affirmativ. Wie sich diese Germanistik methodisch und historisch rechtfertigte, sei im folgenden skizziert.

\subsection{Sprachbegriff: Gemeinschaft - Rasse - Volksgeist}

Das Sprachdenken nationalistischer Germanistik setzt auf den Begriff der sprachlichen Gemeinschaft. Diese von Humboldt übernommene Vorstellung trägt diese Germanistik 1933 ff. zuallererst ${ }^{8}$ : ,Sprache [...] erzeugt im geistigen Sinne erst die Gemeinschaft, die wir Volk nennen und bleibt dauernd der eigentliche Erzieher zur Volkheit und deren besonderer geistig-seelischer Haltung, die [...] in weitem Maße von ihr bestimmt ist" [40, 383]. Natürlich einer Position, welche Sprache als soziale Erscheinung beschreibt, ist zu folgen: „Das Wesensverhältnis von Sprache und Mensch läßt sich [...] nur aus dem Verhältnis von Sprache und Gemeinschaft bestimmen, und das eigentliche Subjekt der Sprache ist das Wir der Gemeinschaft, nicht der Einzelne. Diese beiden Strukturen Sprache und Gemeinschaft sind wesentlich aufeinander bezogen [...] Sprachgemeinschaft ist eine mit der Sprache gesetzte Grundform menschlicher Gemeinschaft. Sie besteht durch das gemeinsame Welterlebnis im Zeichengefüge einer Sprache“ $[58,16]$. Aber: Die Emphase, mit der auf diesen Begriff gesetzt wird, und die Tatsache, daß die Gemeinschaftsidee eine dem Nationalsozialismus besonders förderliche Vorstellung bietet, läßt den Begriff zum Nazi-Wort geraten: „In unserem geschlagenen, im sogenannten Frieden noch mit sadistischer Lust gepeinigten Volke drohte der Gemeinschaftsgedanke sich [...] zu verlieren, erstickt von dumpfer Not und von

${ }^{8}$ Was die völkische Germanistik mit Fleiß übersah, war hier die Bedeutung, die Humboldt dem Individuum bei der Prägung der Sprachgestalt beimaß: „Individualitaet ist Einheit der Verschiedenheit“ (Nationalcharakter, 64), und „Sprache erhält durch Individualität Charakter und wirkt im Charakter zurück" (ebd. 68) - solche Thesen vertrugen sich schlecht mit dem ausschließlich auf ,Gemeinschaft" setzenden methodischen Ansatz. 
trostlosem Klassenkampfe, in der furchtbaren bolschewistischen Bewegung zum bloßen Gedanken der Masse entstellt und erniedrigt. Der Sieg des Nationalsozialismus griff rettend ein und hat den erlöschenden Funken zu höchster Helle und Wärme entfacht. Bindung in der Gemeinschaft ist heute die beherrschende Losung deutschen Lebens" [40, 377]; dann die Wendung zur Sprache: „Volkheiten möchte ich nach ihrer geistigen Seite definieren als geschlossene geistige Verkehrsgemeinschaften, denen die einheitliche und eigentümliche Sprache sowohl wesentliches Mittel der Herstellung, Abgrenzung und Erhaltung solcher Gemeinschaft, als ihr wesentlicher Ausdruck ist" [ebd. $379 \mathrm{f}$.]. Unentrinnbarkeit - der Mythos des Schicksals hat sich im Nationalsozialismus bewährt, so auch als sprachliches Konzept im Sinn einer Bestimmung des Gemeinschaftsbegriffs: „Wenn es wahr ist, was neuere Forschung behauptet, daß Sprache es vor allem ist, was[!] die Gesichtszüge einer Volksgemeinschaft typisch gestaltet, so tragen wir Deutsche alle die Schicksalszüge unseres Volkes im Antlitz" [ebd. 384]; an anderer Stelle: „So ist die Sprache gewiß die Schicksalsmacht, die am nachhaltigsten unsere gesamte geistige Entwicklung beeinflußt" $[9,364]$. Besonders in Kitsch und Pathos läßt sich der sprachliche Gemeinschaftsbegriff vergegenwärtigen: „das Gemeinschaftserlebnis [ist] für den Sprachwissenschaftler nicht Klausel eines Arbeitsabkommens, sondern birgt bedeutungsvollste Tiefe: in sinnvoller Übereinstimmung mit seinem Forschungsobjekt, der Sprache, die die eine soziale Kraft im Aufbau der Gesamtkultur ist, sieht sich der Forscher in der Feier der Gemeinschaft zu jenem Punkt herangeführt, wo seine Wissenschaft, die über das Fachliche hinaus sich als Glied der gesamten Kulturwissenschaft empfindet, nun unmittelbar Anschluß gewinnt an eine zentrale Grundkraft deutschen Lebens, an das Gemeinschaftsgefühl, das so lang vergessene" $[57,199]$.

Deutsches Wesen, deutsches Blut, deutsches Schicksal - mit solcher Mystifizierung des Gemeinschaftsbegriffs wird Nationalismus betrieben, der auch Abgrenzung nach außen bedeutet: Deutschtum hie - alles Nichtdeutsche $\mathrm{da}^{9}$. Der Weg zum rassistischen Sprachbegriff ist damit eingeschlagen: „[Sprache] hilft Volk bilden, ist selbst doch aber auch von den Kräften des Volkes gestaltet“ $[15,360]$. Diese Vorstellung wird unermüdlich beschworen: „In ihnen [den Sprachen] haben sie [die Völker] in jahrtausendelangem Sinnen und Forschen den unermeßlichen Schatz ihrer Erfahrungen, Erlebnisse und Weistümer niedergelegt, der nun als erwerbbarer Besitz für alle Mitglieder der betreffenden Sprachgemeinschaft bereitsteht. Dieser gemeinsame Schatz ist zugleich das wichtigste Bindeglied, das ein Volk zusammenhält, aus ihm echte Gemeinschaft formt" $[9,361]$. Jubelnd wird da Humboldts Vorstellung der sprachlichen Abgrenzung begrüßt, die die rassistische Germanistik dankbar

9 Wir kennen die aus der nämlichen Geisteshaltung entstammende Nazi-Parole ,Wer nicht für uns ist, ist gegen uns' als Variante. 
aufnimmt ${ }^{10}$. Eine solche Tendenz setzt schon im 19. Jahrhundert ein, und spätestens seit 1918 heißt die ,fachlich kaum mehr eingrenzbare [...] Aufgabe“ der Germanistik „Ergründung deutschen Wesens“ (Lämmert 1967, 27). Schließlich, in der Zeit von 1933 bis 1945, geraten wesentliche Teile der Sprachgermanistik ins wissenschaftliche Abseits. Dies in dem besonderen Sinn, $\mathrm{da} ß$ sie, wie alle Wissenschaften, gleichgeschaltet und dem Totalitarismus Hitlerscher Prägung unterworfen wurde - das hieß für die Wissenschaft ,Deutschkunde ${ }^{11}$. Germanistik ist zur Hilfswissenschaft der alle Wissenschaft überragenden ,Rassenkunde c - das ist ein anderer Name für dasselbe Konzept - degradiert, und in keiner anderen Hinsicht manifestiert sich ihre Politisierung deutlicher: „Wie groß ist [...] der Wandel im Sinngehalt unserer Sprache! Mit dem Rassengrundsatz als tragendem Pfeiler der Bewegung ist die an sich junge Rassenkunde [...] an die Spitze aller Wissenschaften getreten. [...] Mit den neuen Sinninhalten ist ein allmählicher Umbau unseres gesamten wissenschaftlichen Sprachgutes unausbleiblich. Es muß künftigen Sonderbetrachtungen überlassen bleiben, diese sprachliche Umwälzung im einzelnen festzustellen“ [44, 299 f.]. Mit dem Rassebegriff erklärt Humboldt nicht die Verschiedenheit der Sprachen, seine Begriffe waren bekanntlich ,Volk' und ,Nation'. Rassistische Germanistik leitete aber aus seiner Betonung der sprachlichen Unterschiede ungeniert eine ,blutbedingte' Ursache ab, Nazi-Germanistik richtet dieses Sprachdenken hemmungslos auf ihr Grundthema aus: „Es ist außer allem Zweifel, daß jede Rasse eine ihr gemäße Sprache besitzt, daß also, umgekehrt, jede Sprache auf ein Früheres, Grundlegendes - eben die Rasse - zurückdeutet. Ich glaube, es ist nachweisbar, daß die deutschsprechenden Juden nicht deutsch im eigentlichen Sinne sprechen " $[25,344]$. Bemerkenswert ist hier der Fall Schmidt-Rohrs. Zunächst lehnt er den rassisch gegründeten Sprachbegriff $a b$, so in seinem vielbeachteten und umstrittenen Buch ,MutterSprache‘: „Wer das Wesen der aus dem geschichtlichen Schicksal einer Gruppe geborenen jeweilig vom Menschen abhängigen Sonderartigkeit des ,Zusammengriffs' im Begriff verstanden hat, wer die kräfteformende, ja kräfte-

10 R. Römer möchte in diesem Umstand keinen reinen Mißbrauch erkennen: „Eine auf Unterschiede zwischen den Völkern versessene Ideologie hat Humboldt benutzt, zum Teil umgedeutet, aber man kann nicht sagen, daß sie ihn total mißbraucht und verfälscht habe" $(1985,138)$.

11 Die Bestürzung über diese schamlose Preisgabe des Grundprinzips der Bildung, die der Menschlichkeit, läßt sich nicht beschreiben: „Letzter Sinn der Universitätserziehung war bisher die Humanitas, die Menschlichkeit, letzter Sinn der nationalsozialistischen Erziehung muß im dritten Reich sein die Erziehung zur deutschen Volkheit“ (Weller 1933, 7). Ein Gegenbegriff zu Totalitarismus ist Pluralismus, ein Gegenbegriff zu Diktatur ist Demokratie - im Staat Hitlers ist nazifreundliche Germanistik NichtWissenschaft in dem Sinn, daß sie sich nicht mit Gegenentwürfen auseinandersetzt - nämlich im humanistischen, vorbehaltlos prüfenden, objektiv wägenden, neutral analysierenden Sinn - , sondern sich selbst a priori als Maßstab voraussetzt, damit anderes schmähend herabsetzt statt argumentierend bewertet, was nicht dem ideologisierten Ansatz entspricht. 
weckende, lebendige Wesensart der Sprache erfaßt hat, der kann von vornherein nur lächeln über die ganz und gar unsinnige Vorstellung von der sonderweltlichen, einer Rasse eigentümlichen , arteigenen' Sprache" $[46,220]^{12}$. Nachdem er sich aber mit dieser Wahrheit massiven Angriffen ausgesetzt und sein Fortkommen behindert sah, kehrte er seine wissenschaftliche Erkenntnis ins Gegenteil $1^{13}$ : „Die Rasse ist von vornherein eine tiefere Schicht menschlicher Wesensartung als die Sprache. Denn alles, was über das Wesen der Sprache ausgesagt wird, quillt ja letzten Grundes aus der Rasse als der wesentlichsten unter den sprachgebärenden Mächten“ [47, 265]. Wider besseres Wissen seit dem 19. Jh. ist die Zusammenhanglosigkeit zwischen Rasse und Sprache bekannt - wird das Rassekonzept immer wieder beschworen: „Denn Sprache, zunächst naturhaft in Hirn und Mund einer bestimmten Rasse eigenartig entstanden, erzeugt im geistigen Sinne erst die Gemeinschaft, die wir Volk nennen und bleibt dauernd der eigentliche Erzieher zur Volkheit und deren besonderer geistig-seelischer Haltung, die [...] in weitem Maße von ihr bestimmt ist“ $[40,383]$. Im Stil der Deklaration wird unbeirrt festgestellt, „daß die Sprache über der Rasse die größte Macht in einer volklichen Gemeinschaft ist" $[25,344]$. Wenn solches Sprachdenken sich mit nationalistischem Dünkel paart, entstehen aus rassischen Hierarchien sprachliche Wertungen: „Die arthaft deutschen Eigenschaften, die erst eine wahrhaft deutsche Sprachgebung ermöglichen, heißen: Einfachheit, Natürlichkeit, Kraft und in Selbstzucht gebändigter Wille [...] Treffsicherheit der Sprache“ [31, 277 f.]. Der Begriff des von der Phänomenologie eingeführten Begriffs der sprachlichen Leistung wird dann als weitere Stütze des sprachlichen Rassekonzepts verwertet: „Vom Boden möglicher Spracherfahrung aus ist heute namentlich die Frage nach der Leistung der Sprache als schicksalhafte Bildnerin und Erzieherin der Menschheit fruchtbar geworden“ [ebd. 47]. Insofern also „die Leistung der Sprache als einer völkischen Erkenntnisform und einer volksbildenden Macht“" $[9,358]$

${ }^{12}$ Schmidt-Rohr handelte in gutem Glauben, der in seiner Naivität tragische Züge hat: „Aus solcher verantwortungsbewußten Freiheit gibt mein Buch, bei aller jubelnden Begeisterung für den großen deutschen Staatsmann Hitler und seine Bewegung, doch keinesfalls nur einen Kommentar zu einer parteiamtlichen wissenschaftlichen Meinung. Ich mache von der gerade von Hitler selbst immer wieder zugesicherten geistigen Freiheit der Wissenschaft Gebrauch, die kein Dogma aus einzelmenschlicher Setzung anerkennen darf, so sehr sie im Politischen zur letzten Disziplin bereit sein muß" [46, VIII]. Der Grund für die Ablehnung dieser Position Schmidt-Rohrs wird manifest, wenn er rassistischen Sprachdenkern Argumente für die Judendiskriminierung nimmt: „Es ist unendlich naiv, die Verschiedenheit der Lautsysteme aus rassischer Verschiedenheit der Sprachorgane abzuleiten [...] Der Einwand, daß ja der Jude an seiner Sprache zu erkennen sei, ist hinfällig. Denn durchaus nur, wo schon eine jüdische Umgebung - wie ein bäuerisches oder Sattlermilieu - sich als eine Untergruppe der hochsprachlichen Sprechweise darstellt, ist der Jude an seiner Sprache zu erkennen. Nie aber ein Jude, der in nicht-jüdischer Umgebung aufwächst“ [ebd. 227].

13 Das hat sich gelohnt. Schmidt-Rohr war dann Leiter der sprachsoziologischen Abteilung der SS. 
unumstritten scheint, insofern Rassen zudem nach Hierarchien vorgestellt werden ${ }^{14}$, insofern schließlich - das finale Moment nationalsozialistischen Denkens - die jüdische Rasse die unterste Ebene dieser Rangordnung einnimmt, insofern also erhält die Diffamierung scheinbar wissenschaftlich fundierte Substanz: Der Leistungsbegriff verknüpft mit rassistischem Sprachdenken - der Diskriminierung wird ein scheinwissenschaftliches Argument beigelegt. Die Aufgabenstellung ,Erforschung jüdischer Elemente in der deutschen Sprache' erhält so durch die künstlich zum Problem gemachte Sprache-VolkFrage - die ,gerade in Zeiten politischer Not ihre besondre Ausweitung und Vertiefung erfahren konnte“ $[57,198]$ - einen vorgeblich wissenschaftlichen Grund. Für die in antisemitische Dienste gestellte experimentelle Phonetik heißt das etwa: „Sie geht daran, durch Experimente einerseits jüdische Elemente im deutschen Schrifttum herauszuhören [...], andererseits über Sprachmelodie und Psychologie die Brücke zur stammlichen Rassen-Seelenkunde zu schlagen" [ebd.]. Tatsächlich haben wir es hier nicht mit einer wissenschaftlichen Aufgabenstellung zu tun, sondern mit einer psychologischen Kompensationsstrategie. Angst ist ihr Motiv: „Der Jude hat es verstanden, sich auch im Stil dem des Volkes anzugleichen. Unzweifelhaft liegt aber darin die große Gefahr, daß hohe und wichtige Dinge durch einen solchen Stil herabgezogen werden. Effekthascherei kann man diese Vergewaltigung der Sprache nennen“ [5, 60]; und: „Es lohnt sich wohl einmal festzustellen, welche große Menge jüdischer Wörter unser judengegnerisches deutsches Volk unbesehen täglich im Munde führt. Diese unschönen Brocken, die für jeden Wissenden einen so üblen Geruch ausströmen, sollten allgemein angeprangert werden, damit Schule und NSDAP-Organisationen dagegen ankämpfen können“ " 27,456$]$.

Die Vorstellung von der rassebedingten Gestalt der Sprache erhält schließlich Nahrung von dem von der phänomenologisch orientierten Sprachphilosophie eingeführten Begriff des sprachlichen Geistes. Insofern diese Philosophie „Geist [als] die alleinig wirkende Ursache sämtlicher Sprachformen“ (Voßler $1904,63)$ vorstellt, setzt sie den bewußt handelnden Sprachteilnehmer voraus. Der Begriff ,Geist“ bietet dabei die Möglichkeit perfider Auslegung: „Der denkende Geist (und damit der urteilende und handelnde) lebt von Gnaden der heiligen Mächte der Wirklichkeit, die der Nationalsozialismus Blut, Boden, Art, Rassenseele nennt" $[20,470]$. So erfährt der Sprachbegriff in völkischer Version seine kontrastive Ausdeutung: „Um das Reich des Geistes, des deutschen Geistes geht es heute, der in der Sprache nicht nur ein Ausdrucksmittel gefunden hat, der sich vielmehr auch in der Sprache als der eine geistige Artung schaffenden Kraft überträgt auf jedes Geschlecht der neu vom Volkstum Hinzugeborenen oder Hinzugeworbenen" [46, IX]. Sprache bedeutet demnach die Reflexion von ,Volksgeist" in der Begrifflichkeit des sprachlichen Geistes: „Die Sprachen sind nicht nur Erzeugnis, Ergebnis der Nationalseele, Form

${ }^{14}$ Hier hat Humboldt mit seinen durchaus wertenden Betrachtungen der Sprachen bestimmter Völker keinen geringen Anteil. 
gewordener Volksgeist, sondern sie sind dem einzelnen gegenüber ganz und gar der Volksgeist selbst als lebendige, formende, gestaltende Kraft, als Kraft und als eigenartig geprägte und gerichtete, sonderpersönlichkeitliche Kraft. Sprache ist der lebendige, zeugungsgewaltige, schöpferische Volksgeist selbst, in dem und aus dem die Menschlichkeit all der einzelnen Volksglieder erst erblüht" [ebd. 98].

Die geistige Kraft des sprachschöpfenden Menschen und der Einfluß des Volkscharakters auf die Sprache - bei der Zusammenführung von Zeichen und Wirklichkeit im Sinn der begrifflichen Ordnung von Welt fließen sie demnach ineinander: „Entscheidend ist, daß die Ordnung der Tatbestände an sich in den Sprachen von einer jeweils verschiedenen ,künstlichen', menschlichen begrifflichen Ordnung überdeckt wird, von den zwischen Gegenstand und Mensch schwebenden Begriffen und Denkformen; daß in den verschiedenen Sprachen mithin gruppensubjektive Formen des Erkennens zu sehen sind, aus Gruppenschicksalen erwachsene geistige Weltordnungen, Prägungen zu volkhaftem Sein und also nicht bloße abbildende, wiederholende Spiegelungen eines Jenseitigen, sondern urbildliche Welten, deren Gesetz und Ursprung [...] in einer eigenwilligen Schöpfung des Geistes selbst zu suchen ist und in denen allein wir das besitzen, was wir die ,Wirklichkeit' nennen" $[58$, 38 f.]. Erst der Mensch schafft also mit seiner die Welt ordnenden Sprachtätigkeit die Wirklichkeit - diese Theorie ist für den Nationalsozialismus wichtig. Denn in ihr ist die Vorstellung von manipulierbarer Sprache aufgehoben. Wenn der menschliche Geist sprachprägende Instanz ist, wird Sprache disponierbar - das nationalsozialistische Engagement hinsichtlich sprachpolitischer und spracherzieherischer Maßnahmen gehört in diesen Zusammenhang ${ }^{15}$. Darin sieht Nazi-Germanistik ihre Chance: Sprache verändern heißt Menschen verändern und Wirklichkeit verändern. Wenn das Sein eines Volkes auf die Gestalt der Sprache einwirkt, bedeutet ein neues Sein - und der Nationalsozialismus verstand sich ja als ein solches - die Herausbildung einer neuen Sprache: „Was hier dargestellt wird, ist unter dem Gesichtspunkt durchdacht, daß jeder Zweig der Geisteswissenschaft (also auch die Sprachwissenschaft) seine neuen Aufgaben und Ziele weitgehend auf die nationalsozialistische Erziehungsidee bezieht. Dadurch, daß die Wissenschaft der neueren Sprachen sich in diesen Zusammenhang fügt, büßt sie nichts von ihrer wissenschaftlichen Strenge ein; auch wird vieles von dem, was die vergangene Philologie geleistet hat, als wertvolles Hilfsmittel benutzt[!], neue sprachwissenschaftliche Aufgaben zu meistern und vor allem die fremde Welt so für uns zu erschließen, daß sie in ihrem Sein und Wert und besonders in ihrem sittlichen und politischen Wollen sichtbar und infolgedessen bis zu einem gewissen Grade für uns ,beherrschbar'[!] wird. [...] Wir sind heute dabei, den (naturwissenschaftlichen)

15 Damit werden m. a.W. Sprachveränderungsprozesse - „Der NS-Staat war [...] auf dem Wege, die ganze Semantik des Deutschen unter dem Primat seiner Gesamtideologie und den (daraus abgeleiteten) Normen zu ordnen“" (Steger 1989, 99) - erklärbar. 
Positivismus und den (geistleugnenden) Materialismus in der Sprachwissenschaft zu überwinden, weil wir wissen, daß die Sprache in der geistigen und sittlichen Bildung sowohl des Einzelnen als auch der Gemeinschaft eine viel tiefere und wesentlichere Aufgabe hat als die der bloßen Verständigung, daß die Frage nach der Sprache im Grunde dieselbe ist wie die Frage nach den Menschen. Wir wissen, da $\beta$ erst in der Sprache die ,Welt ${ }^{\circ}$ dem Menschen gegenständlich und faßlich wird und daß, andererseits, die Gegenständlichkeit, der Inhalt und der Wert der ,Welt' weitgehend, ja vielleicht gänzlich von der Sprache abhängt, die ,ich" als Einzelner und als Gemeinschaftsglied spreche" $[25,339$ ff.]. Es erscheint als folgerichtige Konsequenz, wenn dieser Sprachbegriff als Ausdruck einer Lebensform reflektiert wird: „Die völkische Wiederbelebung hat uns Deutsche alle im tiefsten Innern aufgewühlt und hält uns weiterhin in Atem und Spannung. Nicht nur neue äußere Formen unsres Lebens zu schaffen, ist ihr Ziel, sondern unser gesamtes geistiges Leben umzuformen. Ist aber Sprache das Spiegelbild unseres Innern, Sinnausdruck unseres Bewußtseinslebens, so muß auch sie eine neue Wesensgestalt erhalten “ [44, 297]. Mit diesem Sprachbegriff lassen sich auch sondersprachliche Existenzformen beschreiben: „Die Sprache des Arbeitsdienstes ist ein Beispiel dafür, daß geistige Kraft und schöpferisches Vorstellungsvermögen zusammenwirken müssen, um einem neuen Gedanken die Bahn freizumachen. So wie die nationalsozialistische Bewegung ihr Gedankengut in Rede und Schrift als etwas Neues schuf, so wie die weitgespannte Weltanschauung neue Bilder, Begriffe, Formen und Wortverbindungen prägte, so war es auch bei den grundlegenden Äußerungen über den Arbeitsdienstgedanken“ [14, 199]. Hierher gehört zudem die Erklärung der ,rhetorischen' Macht Hitlers, verbunden mit der Formulierung einer daraus abgeleiteten Verpflichtung: „Wäre die Sprache nicht eine mächtige Herrin, wo wäre die Wirkung der Worte des Führers geblieben? Seiner Idee haben auch wir Neusprachler in Ernst und Treue zu dienen, dadurch, daß wir dem Worte nachforschen, das die Völker um uns bewegt" $[25,356]$.

\section{Beobachtungen zur Beschreibungssprache}

Ein Merkmal von Selbstbild und Sprachdenken, als Resultat der Vorstellung von der gemeinschaftsgeborenen, aus der Rasse, dem ,Blut' entspringenden Sprache, deren Geheimnisse im Grunde unentdeckt bleiben, ist - wir können es erkennen - eine äußerst irrationale Komponente des Sprachbegriffs, die man nicht verleugnet, sondern im Gegenteil als neues Bestimmungsstück von, wissenschaftlich ' ausweist. Die Übereignung an die Politik bedeutet eine Preisgabe nicht nur des Fachs, sondern auch seines zentralen Modus der Wissenschaftlichkeit. Und während die Instrumentalisierung für politische Zwecke das Fach konkretisiert, löst es sich zugleich mit seiner Entwissenschaftlichung gleichsam auf: „Die höchste und am meisten berechtigte Kennzeichnung des ,Wissenschaftlichen' scheint mir darin gegeben zu sein, [...] daß 
es allein eine Frage der Gesinnung ist" [46, XII]. Naiv mutet die Selbsteinschätzung des Wissenschaftlers an: „[Es läßt sich] nicht beweisen [...], was wissenschaftlich ist. Es läßt sich nur bekennen, was man für wissenschaftlich hält. Und dieses Bekenntnis wird je danach ausfallen, was für ein Mensch einer ist" [ebd. XIII]. Die beschriebene Selbsteinschätzung, gepaart mit einer Apotheose der deutschen Sprache - „wegen der großartigen Entwicklung des deutschen Geistes in einem stolzen Kulturaufstieg müssen wir uns dieser Sprache voll gehobenen Selbstbewußtseins freuen. Von den tausend Sprachen unseres Erdballs können sich nur wenige mit der unsrigen vergleichen" [ebd. 203] - mündet in den Verzicht auf wissenschaftliche Selbstbestimmung und zeigt den Sprachforscher als Gefesselten, der sich willig dem Numinosen ausliefert. Manifestiert sich in der Unterwerfung unter den wissenschaftlichen Gegenstand, in dem Wunsch, gleichsam von ihm beherrscht zu werden, eine Übertragung des Führerbegriffs? Zumindest erkennen wir gewollte Unwissenheit, mythisch-religiöse Gläubigkeit als neue Haltung der Wissenschaft - sie überläßt sich derjenigen Bequemlichkeit, die enge Erkenntnisgrenzen akzeptiert: „das Ganze mit allen Einzelheiten ins helle Licht des Tages zu stellen, dürfte schwerlich je gelingen. Genug denn, wenn wir lernen, vor der Sprache mit jener stillen Verehrung zu stehen, die allem im letzten Sinne Unerforschlichen gebührt. Das Mysterium der Deutschheit nannte Nietzsche unsere Sprache und vor dem Heiligsten hebt sich nie der letzte Schleier" [40, 389]. So ist der Sprachbegriff geprägt: „Die deutsche Sprache [...] wirkt aus dem Lautgewordenen Bildgeheimnis deutschen Wesens und zieht uns unbewußt in ihren Bann. Sie ist zusammen mit den Bildgeheimnissen des Blutes und der Landschaft die gewaltige Wirkerin unseres artbedingten Schicksals. Wenn wir sie verderben, verderben wir Deutschland“" $[20,475]$. Diese neue Haltung offenbart sich zudem etwa, wenn Schmidt-Rohr das Wesen von Sprachkritik dunkel beschreibt: Sie „braucht [...] nicht in den pathetischen Pessimismus Mauthners auszumünden. [...] Uns ängstet heute eine frei im Raume schwebende Welt, eine sich wandelnde Wahrheit nicht mehr in eine solche trostlose Erschütterung. Wir fühlen uns in den Dämmerungen eines neuen philosophischen Zeitalters, das die Grenzen freudig bejaht, das die Wahrheitswerte des Irrationalen, ja des Antirationalen entdeckt, das den heimlichen mütterlichen Glanz der Sprache ahnt und sie zu lieben vermag, trotzdem und weil sie das Netz eines sonderartigen Schicksals über uns wirft" $[46,131]$.

Solche Absage an eine von Erkenntniswillen getragene Arbeitshaltung ist der Grund für eine Beschreibungssprache, die mystifiziert und verdunkelt, statt $\mathrm{zu}$ klären und $\mathrm{zu}$ erhellen. Eine Zusammenstellung von Irrationalismen und Gefühlsausdrücken aus einem Zeitschriftenbeitrag des Jahres 1935 [20] dokumentiert Befangenheit und Obsession: „[Wort, das] schicksalkündende Einblicke gewährt", die „wesenmeinende Unterschicht der Nomen“, „Sprachwirkung beruht $[\ldots]$ in den vorvernünftigen Quellen der Sprache“, „Klangbildgeheimnisse der [...] Vokale“, „die Geheimnisse der Zeugung und des Todes [in dem Laut /u/]“, „symbolisches Geheimnis der Sprache“, „Gesetz der Laut- 
magie“, „Urwörter [als] Sinnbilder von Erscheinungen, die zugleich als seelische Wirklichkeiten erlebt wurden“, „das Wort [das] auf den geheimnisvollen, symbolischen, nur zu erlebenden Wortgrund hindenkt". Solche Unterwerfungsattitüde enthebt von der Verpflichtung, durch terminologische Prägnanz den wissenschaftlichen Gegenstand der Überprüfbarkeit auszusetzen, der wissenschaftlicher Objektivität nicht stand hält ${ }^{16}$. Unter diesen Voraussetzungen kann sich eine ,Wissenschaftssprache' entfalten, die Mystizismen an die Stelle von Termini setzt, Archaismen an die Stelle durchsichtiger Beschreibungssprache, unerträgliches lautes Pathos an die Stelle wissenschaftlichen schlichten Realismus: „Das Wort, das sich mit deutscher Innerlichkeit durchtränken läßt, wird [...] zum edlen Schrein, der dem Sprechenden wie dem Lauschenden aufspringt und kostbaren Inhalt darweist" $[12,74]$. Kryptische Formulierungen stellen einen Gegenentwurf dar zu dem, was als Wissenschaftssprache - „Der wissenschaftliche Jargon ist so klebrig, daß es schwer ist, ihn von den Fingern zu bekommen" [46, XII] - abgelehnt wird. Denn insofern der Wissenschaftler „heute keine Wissenschaft mehr um der Wissenschaft willen, sondern zum Besten seines Volkes treibt, [...] muß er seine gelehrten Arbeitsergebnisse auch in eine gemeinverständliche Form gießen können“ $[52,195]$. Wissenschaftssprache sei deshalb „volkstümlich, gemeinverständlich und lebenswarm“ [ebd. 196]. Kitsch hat danach System und führt zu schwer erträglicher Metaphorik: „Alles Leben, mit dem sie [Wörter wie Vaterland, Frühling, Blüte, Wein] auf ihrem Gang aus Urahnentiefe sich vollsogen von Geschlecht zu Geschlecht, das Freudige, das aus Millionen Herzen darin haften blieb, wer sie oberflächlich schwatzt, spürt davon nichts. Aber sie lassen sich so zum Klingen bringen, daß uns ein Duft daraus anweht wie von einem Tropfen Rosenöl, darin viel tausende Rosen hauchen. Dann werden sie zum Zauberwort, das ein Wesen enthüllt“" $[12,71]$.

Die Entfernung des linientreuen Fachs von dem, was ,wissenschaftlich meint und das in solch kryptische Darbietungsweisen seiner Ergebnisse mündet, hat ein weiteres zur Folge. Ideologisierte Sprachgermanistik $1933 \mathrm{ff}$. ist eine wertende ,Wissenschaft ${ }^{t}$, die nur gut oder schlecht kennt, Hochachtung oder Geringschätzung, Auf- oder Abwertung. Die Beschreibungssprache aus diesem Geist hat nichts mit wissenschaftlicher Objektivität und Prägnanz zu tun, kann sie, soll sie auch gar nicht. Denn die Wertung ist ja der eigentliche Zweck - gute Sprache ist die volkstümliche Sprache, Soldatensprache, Sportsprache. So widersprüchlich die Bestimmungsstücke sind - ,bedeutungsschwer' und ,verständlich', ,monumental' und , anschaulich', ,hart' und ,bildsam‘, ,stolz' und ,wirksam' heißen sie -, martialisch geprägte Sprachökonomie vor allem ist Leitbild: „gerafft', ,zuchtvoll‘, ,klar' - dies besonders - , ,bestimmt', ,schlicht', ,schweigsam'[!], ,knapp', ,straff', ,bündig', ,kargbemessen',

16 Als „Stigma vollendeter Unwissenschaftlichkeit“ (Ziegler 1965, 150) beschrieben, zeigt sich auch in diesem Aspekt die Disponiertheit der völkischen Germanistik zum bekanntermaßen wissenschaftsfeindlichen Nationalsozialismus. 
,einfach', ,gehalten', ,sachlich', ,kämpferisch', ,soldatisch', ,heldisch' heißt das Sprachideal; daneben auch hier das bekannte, von biologischem Denken geprägte Bild: Sprache sei ,gesund', ,echt', ,natürlich'. Dagegen finden sich bemerkenswert wenig Urteile zur schlechten Sprache der Intellektuellen und der Wissenschaft, sie ist ,farblos', ,langatmig', ,geschwätzig', ,schillernd', ,blendend', ,zerfasernd'.

Diese quer durch die dokumentierten Beiträge zusammengestellten Werturteile sind ein Resultat des zuvor dargelegten Selbstverständnisses. Wir fassen zusammen: Ideologisierte Sprachgermanistik 1933 bis 1945 tendierte dazu, sich als Wissenschaft aufzugeben. Sie hat den Wissenschaftsbegriff denunziert und sich dem Totalitarismus Hitlers angedient. Dessen Merkmale sind es, welche das unterwürfige Fach dieser zwölf Jahre zeichnen. Wissenschaftliche Offenheit ist aufgegeben zugunsten einer Weltsicht der engen Grenzen, die Vorgefaßtes lediglich reproduziert. Wissenschaftliche Erkenntnis ist ersetzt durch Gläubigkeit und Mythos. Wissenschaftliche Neutralität und Objektivität wird ignoriert zugunsten einer Wertung, deren Maßstab nicht aus dem wissenschaftlichen Gegenstand, sondern aus dem außerhalb ihrer selbst liegenden Zweck abgeleitet ist. Das Selbstverständnis des Fachs, seine Auslieferung und der Byzantinismus, mit dem es dem Nationalsozialismus begegnete, seien zum Schluß noch einmal dokumentiert: „,Da kommt ein Zug Hajott' (geschrieben: HJ.)! Was sagt das? Es kann nichts anders sagen als: da kommt ein Trupp der in bestimmte Formationen eingeteilten Braununiformierten, auf einem dienstlichen Marschwege. Dagegen: ,Da kommt ein Zug Hitler-Jugend!', das heißt: sieh die frischen Burschen, wie sie im Takt ihrer Pfeifen freudig hinausziehen, alle dem Stern nach: Hitler ihr Führer! Kann das ein Mensch in "Hajott" hineinlegen? Aber aus ,Hitler-Jugend' blüht es auf! Und wenn ein rotbackiges Kerlchen in seiner Begeisterung es fertig bringt, sogar ,Hajott' $\mathrm{zu}$ beseelen, ist das nicht schade um das verschüttete Leben, das aus Wörtern wie ,Hitler und ,Jugend" quillt?" $[12,67]$. Angesichts dieses Textes müssen wir Sprachlosigkeit zugeben und fragen: Wie läßt sich solch ein Aberwitz beschreiben? Der Autor Ewald Geißler war Duden-Mitarbeiter und vorgesehen als Leiter des (dann nicht realisierten) Sprachamtes der Deutschen Akademie.

\section{Literaturverzeichnis}

Ahlzweig, Claus (1989): Die deutsche Nation und ihre Muttersprache. In: Ehlich, Konrad (Hg.), a. a. O., 35-57.

Bauer, Gerhard (1988): Sprache und Sprachlosigkeit im ,Dritten Reich‘. Köln.

Berning, Cornelia (1964): Vom ,Abstammungsnachweis` zum ,Zuchtwart'. Vokabular des Nationalsozialismus. Berlin.

Bohleber, Werner/Jörg Drews (Hgg.) (1991): ,Gift, das du unbewußt eintrinkst ...'. Der Nationalsozialismus und die deutsche Sprache. Bielefeld.

Brackmann, Karl-Heinz/Renate Birkenhauer (1988): NS-Deutsch. ,Selbstverständliche Begriffe und Schlagwörter aus der Zeit des Nationalsozialismus. Straelen.

Dornseiff, Franz (1933 f.): Der deutsche Wortschatz synonymisch geordnet. Berlin und Leipzig. 
Ehlich, Konrad (Hg.) (1989): Sprache im Faschismus. Frankfurt am Main.

Greß, Franz (1971): Germanistik und Politik. Kritische Beiträge zur Geschichte einer nationalen Wissenschaft. Stuttgart.

Humboldt, Wilhelm von: Ueber den Nationalcharakter der Sprachen. Werke in fünf Bänden III. Schriften zur Sprachphilosophie. Herausgegeben von Andreas Flitner und Klaus Giel. 5. unveränderte Auflage, Darmstadt 1979.

Jacob, Hans (1938): An ihrer Sprache sollt ihr sie erkennen. Die Gleichschaltung der deutschen Sprache. In: Das Wort Bd. 1, 81-86.

Lämmert, Eberhard (1967): Germanistik - eine deutsche Wissenschaft. In: Germanistik - eine deutsche Wissenschaft. Beiträge von Eberhard Lämmert, Walther Killy, Karl Otto Conrady und Peter von Polenz. Frankfurt am Main, 7-41.

Maas, Utz (1984): Als der Geist der Gemeinschaft eine Sprache fand. Sprache im Nationalsozialismus. Opladen.

Maas, Utz (1988 a): Die Entwicklung der deutschsprachigen Sprachwissenschaft von 1900 bis 1950. Zwischen Professionalisierung und Politisierung. In: Zeitschrift für germanistische Linguistik 16, 253-290.

Maas, Utz (1988 b): Sprachwissenschaft und Nationalsozialismus. In: Semiotische Berichte $12,249-264$.

Maas, Utz (1991): Sprache im Nationalsozialismus: Macht des Wortes oder Lähmung der Sprache. In: Bohleber, Werner/Jörg Drews (Hgg.), a. a. O.

Paechter, Heinz (1944): Nazi-Deutsch. A glossary of contemporary German usage. With appendices on government, military and economic institutions. New York.

Polenz, Peter von (1967): Sprachpurismus und Nationalsozialismus. In: Germanistik eine deutsche Wissenschaft, a. a. O., 111-165.

Römer, Ruth (1985): Sprachwissenschaft und Rassenideologie in Deutschland. München.

Simon, Gerd (1979): Sprachwissenschaft und politisches Engagement. Zur Problemund Sozialgeschichte einiger sprachtheoretischer, sprachdidaktischer und sprachpflegerischer Ansätze in der Germanistik des 19. und 20. Jahrhunderts. Weinheim.

Simon, Gerd (1982): Zündschnur zum Sprengstoff. Leo Weisgerbers keltologische Forschungen und seine Tätigkeit als Zensuroffizier in Rennes während des 2. Weltkriegs. In: Linguistische Berichte 79, 30-52.

Simon, Gerd (1985): Sprachwissenschaft im 3. Reich. Ein erster Überblick. In: Politische Sprachwissenschaft. Hg. von Franz Januschek. Opladen, 375-396.

Simon, Gerd (1986): Wissenschaft und Wende 1933. Zum Verhältnis von Wissenschaft und Politik am Beispiel des Sprachwissenschaftlers Georg Schmidt-Rohr. In: Das Argument 158, 527-542.

Simon, Gerd (1989): Sprachpflege im ,Dritten Reich‘. In: Ehlich, Konrad (Hg.), a. a. O., $58-86$.

Steger, Hugo (1989): ,Verwirrung' als Ergebnis zeit- und kulturkritischer Analyse Zukunftsphantasien in ,Ganzheitsmythen' - Erwachen im ,Totalitarismus'. In: Kreutzer, Helmut/Dieter Zerlin (Hgg.): Verfolgung und Widerstand. Acta Ising 1988. München, 81-101.

Stötzel, Georg (1988): Nazi-Verbrechen und öffentliche Sprachsensibilität. Ein Kapitel deutscher Sprachgeschichte nach 1945. In: Horst Haider Munske u. a. (Hgg.): Deutscher Wortschatz. Lexikologische Studien. Berlin, New York.

Voßler, Karl (1904): Positivismus und Idealismus in der Sprachwissenschaft. Heidelberg. Weller, Maximilian (1933): Nationalsozialistische Universitätsreform und Philosophische Fakultäten. Köln.

Wigger, Arndt (1982): Bibliographie: Sprachwissenschaft und Faschismus. In: Osnabrücker Beiträge zur Sprachtheorie 21, 105-119. 
Ziegler, Klaus (1965): Deutsche Sprach- und Literaturwissenschaft im Dritten Reich. In: Deutsches Geistesleben und Nationalsozialismus. Hg. von Andreas Flitner. Tübingen, $144-159$.

Adresse der Verfasserin: Dr. Heidrun Kämper-Jensen, Seminar für deutsche Sprache und Literatur, TU Braunschweig, Mühlenpfordtstraße 22/23, D-38106 Braunschweig. 